GABRIELA Rodrigues SAAB RIVA

\title{
O DIREITO INTERNACIONAL E OS Testes de Medicamentos COM SERES HuMANOS
}

Tese de Doutorado

Orientadora: Professor(a) Associada Dr(a). Cláudia Perrone Moisés.

Faculdade de Direito

Universidade de São Paulo

São Paulo

2018 

GABRIEla RodRigues SAAB RiVA

\section{O DIREITO INTERNACIONAL E OS TESTES DE MEdicamentos COM SERES HuManos}

Tese de Doutorado apresentada à Banca Examinadora do Programa de Pós-Graduação em Direito, do Departamento de Direito Internacional e Comparado, da Faculdade de Direito da Universidade de São Paulo, como exigência parcial para obtenção do título de Doutor(a) em Direito, sob orientação da Professor(a) Associada Dr(a). Cláudia Perrone Moisés.

Faculdade de Direito

Universidade de São Paulo

São Paulo

2018 
RIVA, Gabriela Rodrigues Saab. O Direito Internacional e os Testes de Medicamentos com Seres Humanos, Tese de Doutorado, Orientador(a): Professor(a) Associada Dr(a). Cláudia Perrone-Moisés, Departamento de Direito Internacional e Comparado, Faculdade de Direito da Universidade de São Paulo, São Paulo, 2018, 270 p.

1. testes de medicamentos; 2. ensaios clínicos; 3 . direito internacional; 4. direitos humanos; 5. globalização de riscos; 6. socioeconomicamente vulneráveis. 


\title{
FOLHA DE APROVAÇÃO
}

\author{
Gabriela Rodrigues Saab Riva \\ "O Direito Internacional e os \\ Testes de Medicamentos com Seres Humanos"
}

Tese apresentada à Faculdade de Direito da Universidade de São Paulo, para obtenção do título de Doutor(a) em Direito. Área de concentração: Direito Internacional e Comparado

Aprovada em:

Banca Examinadora
Professor(a) Associada Dr(a). Cláudia Perrone Moisés (Presidente da Banca e Orientador(a))

Prof. Dr. Instituição:

Julgamento: Assinatura:

Prof.Dr. Instituição:

Julgamento: Assinatura:

Prof.Dr. Instituição:

Julgamento: Assinatura:

Prof.Dr. Instituição:

Julgamento: Assinatura:

Prof.Dr. Instituição:

Julgamento: Assinatura: 


\section{AGRADECIMENTOS}

Aproveito a oportunidade para agradecer aos amigos, familiares e professores que foram essenciais para a elaboração da presente tese.

Antes de tudo, agradeço à minha mãe, Rosy Rodrigues, e ao meu marido, Fabio Riva, pelo apoio e incentivo de sempre, sem os quais eu possivelmente não teria chegado ao fim dessa tarefa, que, apesar de tão gratificante, é longa e detalhada.

Meus profundos agradecimentos às queridas Mylla Pacheco, Francisca Helena e Regina Riva pelo suporte especial que me deram nos últimos momentos da redação desta tese.

Agradeço também á colaboração, em forma de críticas, sugestões e incentivos, dos caros amigos Lisiane Bastos, Gisélia Galvão, Thiago Assunção, Vivian Rey e Sandor Rezende.

Por fim agradeço especialmente a Professora Cláudia Perrone-Moisés, a qual não apenas me orienta, mas constantemente me inspira a continuar no caminho acadêmico.

A esses e outros que colaboraram para a realização desse sonho, o meu muito obrigada. 


\section{RESUMO}

RIVA, Gabriela Rodrigues Saab. O Direito Internacional e os Testes de Medicamentos com Seres Humanos, Tese de Doutorado, Orientador(a): Professor(a) Associada Dr(a). Cláudia Perrone-Moisés, Departamento de Direito Internacional e Comparado, Faculdade de Direito da Universidade de São Paulo, São Paulo, 2018, 270 p.

A presente tese tem como tema central os testes de medicamentos com seres humanos e objetiva compreender como se dá o seu tratamento pelo direito internacional. Por meio de reflexões jurídicas, éticas e sociológicas, se propõe a analisar as principais questões da experimentação humana sob o ponto de vista da proteção ao participante vulnerável, em especial dos indivíduos e comunidades socioeconomicamente vulneráveis. Para isso, procede, inicialmente, ao estudo dos marcos históricos dos experimentos com seres humanos para, na sequência, contextualizá-los dentro do fenômeno da migração dos testes de medicamentos para países em desenvolvimento. Em seguida, trabalha os principais dilemas éticos dos testes com seres humanos, os quais fornecem o embasamento teórico para a compreensão dos documentos jurídicos internacionais de relevância para o tema. De forma complementar ao estudo do tratamento do direito internacional aos testes de medicamentos, procede ao estudo de sistemas de regulamentação nacionais e regionais - Estados Unidos, Europa, Índia e Brasil -, os quais fornecem elementos para a definição dos princípios e regras mais relevantes da experimentação humana atual. Por fim, o presente estudo apresenta reflexões gerais e proposições com vistas a aperfeiçoar a proteção do participante socioeconomicamente vulnerável em testes de medicamentos realizados em países em desenvolvimento.

Palavras-chave: 1. testes de medicamentos; 2. ensaios clínicos; 3. direito internacional; 4. direitos humanos; 5. globalização de riscos; 6. socioeconomicamente vulneráveis; 


\begin{abstract}
RIVA, Gabriela Rodrigues Saab. International Law and Human Clinical Trials, Tese de Doutorado, Orientador(a): Professor(a) Associada Dr(a). Cláudia Perrone-Moisés, Departamento de Direito Internacional e Comparado, Faculdade de Direito da Universidade de São Paulo, São Paulo, 2018, 270 p.
\end{abstract}

This thesis investigates how international law regulates human clinical trials. Through the application of legal, ethical and sociological frameworks, this study aims at examining the main issues relating to human experimentation and the protection of vulnerable individuals, with focus on those individuals who are part of socioeconomic vulnerable populations. It initially discusses the landmarks of human experimentation, and continues by contextualizing the subject within the recent migration flow of drug testing activities to developing countries. Then, the study investigates the main ethical dilemmas of human experimentation in order to provide theoretical foundations for the analysis of the relevant legal documents on the subject. Complementary to the study of the international regulation of drug testing is the study of national and regional regulations - United States, Europe, India and Brazil - as both contribute to the development of the most relevant principles and rules currently regulating human experimentation. Finally, this thesis provides a number of opinions and propositions to improve the protection of socioeconomic vulnerable individuals in clinical tests that are performed in developing countries.

Key words: 1. drug tests; 2. clinical trials; 3. international law; 4. human rights; 5. risk globalization; 6 . socioeconomic vulnerable 


\section{Sumário}

LISTA DE SIGLAS E ABREVIAÇÕES................................................................7

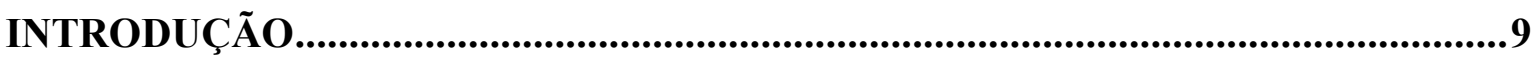

1. Reflexões Iniciais sobre as Pesquisas com Seres Humanos....................................15

1.1. Pesquisas com Seres Humanos na História ...........................................................18

1.2. Pesquisas com Seres Humanos em tempos de "Globalização de Riscos" .................27

2. Principais Dilemas Éticos das Pesquisas com Seres Humanos ...............................39

2.1. Bioética e Pesquisas com Seres Humanos..............................................................39

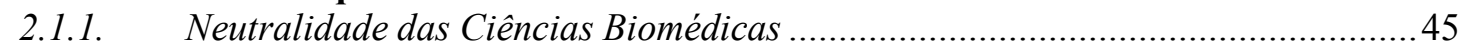

2.1.2. Distinção entre Terapia e Pesquisa ….................................................................5

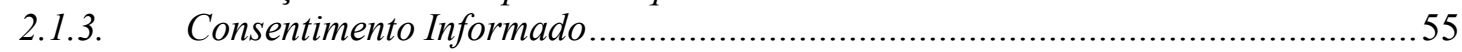

2.2. Pesquisas com seres humanos e vulnerabilidade..............................................................70

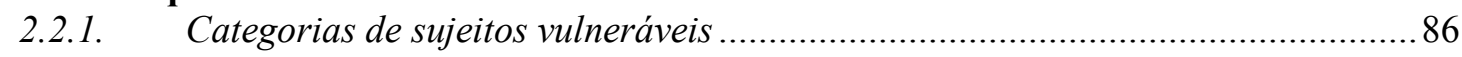

2.2.2. Sujeitos socioeconomicamente vulneráveis de países em desenvolvimento............98

3. Pesquisas com Seres Humanos no Direito Internacional....................................119

3.1. Experimentos Nazistas, Caso Médico e Código de Nuremberg ...............................119

3.2. Associação Médica Mundial e Declaração de Helsinque ..........................................133

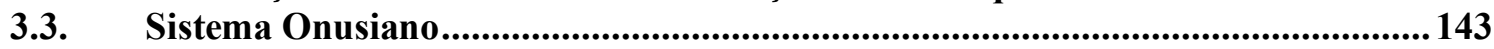

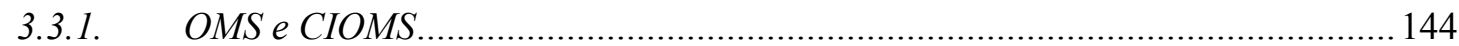

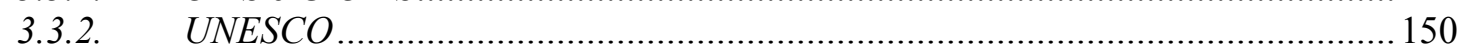

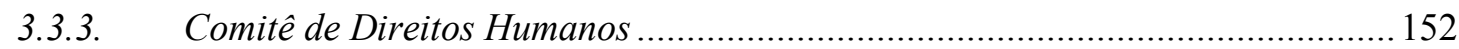

3.4. Conferência Internacional para Harmonização de Requisitos Técnicos para o

Registro de Fármacos para Uso Humano (ICH) ......................................................................157

3.5 Conclusões parciais .......................................................................................................... 158

4. Estudos sobre a Regulamentação Doméstica e Regional das Pesquisas com Seres

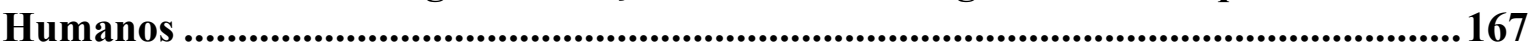

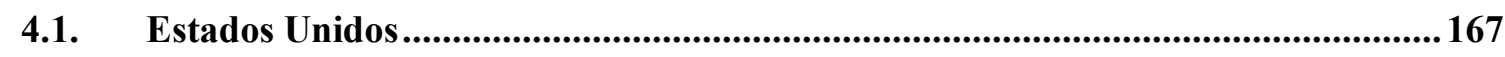

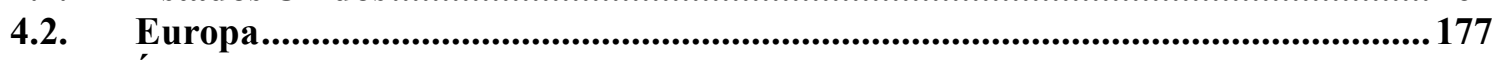

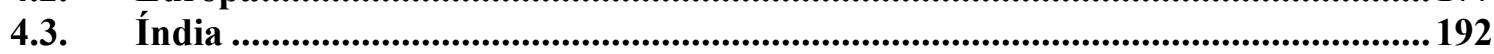

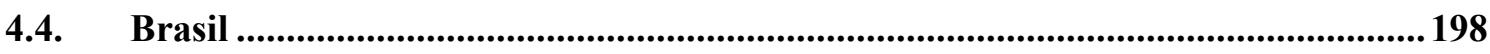

4.5. Conclusões parciais ..........................................................................................................208

5. Reflexões Gerais e Proposições ..................................................................211

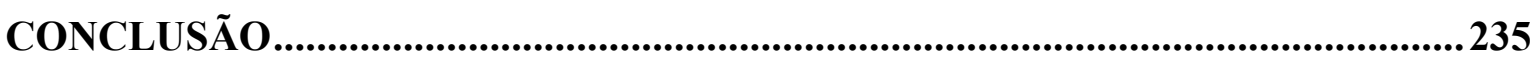

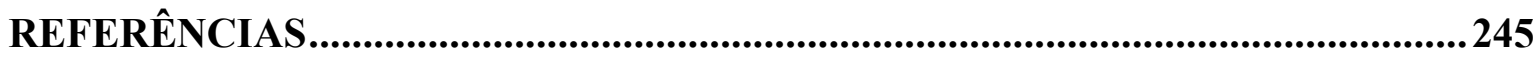

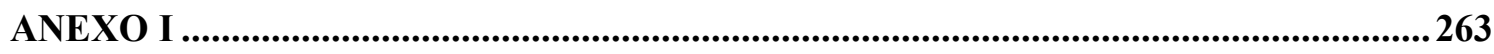

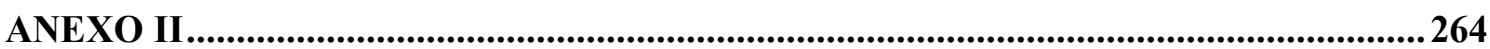

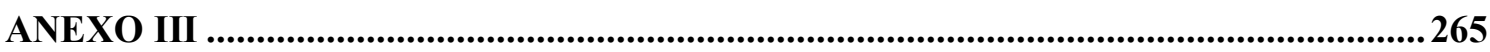

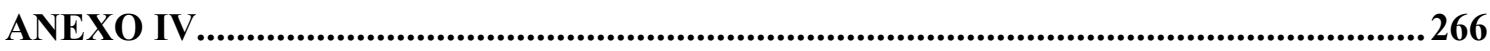

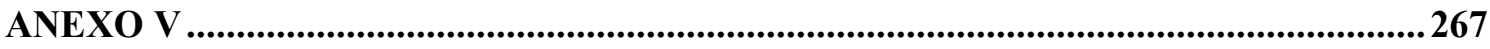

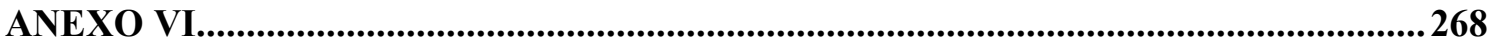

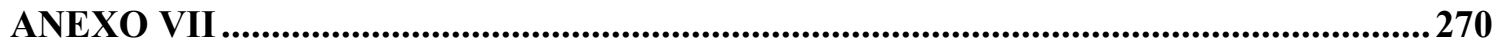




\section{LISTA DE SIGLAS E ABREVIAÇÕES}

AIDS - Acquired immunodeficiency syndrome

AMA - Associação Médica Americana

AMM - Associação Médica Mundial ou World Medical Association (WMA)

ANVISA - Agência Nacional de Vigilância Sanitária

AZT - antiretrovitral zidovudine

BM - Banco Mundial

BR - Brasil

CDC - Centers for Disease Control

CDER - Center for Drug Evaluation and Research

CDSCO - Central Drugs Standard Control Organization

CEP - Comitê de Ética em Pesquisa

CIOMS - Conselho de Organizações Internacionais de Ciências Médicas ou Council for the International Organizations of Medical Sciences (CIOMS).

CNS - Conselho Nacional de Saúde

CNVB - Cadastro Nacional de Voluntários em Estudos de Biodisponibilidade e

Bioequivalência

CONEP - Comissão Nacional de Ética em Pesquisa com Seres Humanos

COP - Conference of Parties

CRO - Contract Research Organization

CSSF - Comissão de Seguridade Social e Família

DCGI - Drugs Controller General of India

DUBDH - Declaração Universal sobre Bioética e Direitos Humanos

EU - European Union

EUA - Estados Unidos da América

FDA - Food and Drug Administration

FMI - Fundo Monetário Internacional

GCP - Good Clinical Practices

HIV - Human Immunodeficiency Virus

HRC - Human Rights Committee

ICH - International Conference on Harmonization of Technical Requirements for

Registration of Pharmaceuticals for Human Use

ICMR - Indian Council of Medical Research 
IND - Investigational New Drug Process

INPI - Instituto Nacional de Propriedade Intelectual

IRB - Institutional Review Board

KOL - Key Opinion Leader

MoH - Ministry of Health \& Family Welfare of India

MS - Ministério da Saúde

MSF - Médicos Sem Fronteiras ou Médecins Sans Frontières (MSF)

NBAC - National Bioethics Advisory Commission

NDA - New Drug Application

NIH - National Institutes of Health

OMS - Organização Mundial da Saúde ou World Health Organization (WHO)

ONG - Organização não governamental

ONU - Organização das Nações Unidas ou United Nations (UN)

PhRMA - Pharmaceutical Research and Manufacturers of America

SUS - Sistema Único de Saúde

TCLE - Termo de Consentimento Livre e Esclarecido

TPI - Tribunal Penal Internacional

UE - União Europeia ou European Union (EU-EEUU)

UNESCO - Organização das Nações Unidas para a Educação, a Ciência e a Cultura ou The United Nations Educational, Scientific and Cultural Organization (UNESCO)

USA - United States of America ou Estados Unidos da América (EUA) 



\section{INTRODUÇÃO}

A experimentação humana é tão antiga quanto as primeiras civilizações, mas foi a partir da metade do século XX que ela tomou proporções nunca antes vistas. ${ }^{1}$ De fato, a evolução acelerada da ciência aumentou a frequência das experimentações com seres humanos e passou a demandar da classe médica e da sociedade em geral a elaboração de regras que estipulassem os limites éticos e legais dos testes.

Antes focada no tratamento e na cura de doenças, hoje a medicina se dedica intensamente à prevenção de doenças, o que aumenta seu escopo e modifica o papel dos testes com seres humanos, os quais passam de ferramenta meramente opcional a obrigação atrelada à prática médica. ${ }^{2}$ Os testes com seres humanos são, portanto, instrumentos cruciais para o desenvolvimento da medicina e continuarão a permitir descobertas terapêuticas e preventivas no futuro.

Não se defende, no presente estudo, a mitigação da atividade da experimentação humana e, por consequência, do progresso da medicina. Ao invés disso, o que se busca é discutir a evolução de sua regulamentação para que a experimentação humana continue a se desenvolver de forma ética e legal, sem que a conduta de alguns indivíduos e instituições provoque danos aos sujeitos que dela participam e, em última análise, ao próprio campo da experimentação humana e da medicina como um todo. ${ }^{3}$ Reiteram-se, dessa forma, as palavras de McCance: “a resposta aos experimentos desumanos é a ênfase nos experimentos humanizados e não a ausência de experimentos". ${ }^{4}$

Dentre as diversas categorias de pesquisas envolvendo seres humanos - sociológicas, psicológicas, clínicas, entre outras -, o presente trabalho discutirá o papel do direito internacional na regulação dos testes farmacológicos, isto é, dos testes realizados para o desenvolvimento de novos medicamentos e vacinas. Discutir-se-á a regulamentação tanto de testes terapêuticos, os quais analisam a eficácia de drogas, como de testes profiláticos, os quais analisam a eficácia da prevenção primária e o desenvolvimento de vacinas.

A escolha do objeto deste estudo se justifica pelo fato de que, dentre todas as pesquisas envolvendo seres humanos, os testes de medicamentos e vacinas são aqueles que

\footnotetext{
${ }^{1}$ BEECHER, Henry K. Research and the Individual: Human Studies. Boston: Little, Brown, 1970, p. ix.

${ }^{2}$ Ibid., p. xi.

${ }^{3}$ Ibid., p. $x$.

${ }^{4}$ MCCANCE, R. A., The practice of experimental medicine. Proc. Roy. Soc. Med. 44:189-194, 1951.
} 
suscitam maiores questionamentos éticos, especialmente por realizarem intervenções diretas no corpo humano. Serão empregados como sinônimos, os vocábulos "experimentação", “ensaio", "teste", “experimentos" e "pesquisa" com seres humanos, os quais referem-se ao estudo sistemático dos efeitos de determinado produto - droga, instrumento ou equipamento - para fins de tratamento, prevenção ou diagnóstico de doença ou condição patológica, com objetivo de descobrir seus potenciais efeitos benéficos ou determinar seus efeitos farmacodinâmicos, farmacológicos e clínicos, além de identificar reações adversas, absorção, distribuição, metabolismo e excreção do produto em investigação. ${ }^{5}$

A experimentação humana é aquela que, individual ou coletivamente, envolve o ser humano, de forma direta ou indireta, em sua totalidade ou em partes, incluindo o manejo de suas informações ou materiais; ${ }^{6}$ envolve tanto a observação quanto mudanças sistemáticas e propositais nas condições do teste, essas também acompanhadas de observação. A "regra de ouro" da pesquisa com seres humanos é o teste controlado por meio da "avaliação dupla às cegas", também chamada de "avaliação cega por pares" (double-blind), o qual divide os participantes em dois grupos: o "grupo de controle", que recebe o tratamento padrão existente, e o "grupo em teste", que recebe o produto experimental. Nesse sistema, tanto participantes quanto pesquisadores não são informados sobre a composição de cada grupo, a fim de que as conclusões finais sejam as mais imparciais possíveis. ${ }^{7}$

Os testes com seres humanos podem ter como participantes - também chamados de sujeitos - indivíduos afetados pela doença em estudo ou voluntários saudáveis. Discutiremos os limites da utilização de indivíduos saudáveis e de algumas mudanças propositais do experimento mais adiante, mas já se pode adiantar que, fosse a experimentação restrita a pacientes e à mera observação da evolução das doenças, a medicina dificilmente estaria no grau de evolução que se encontra atualmente. Por isso também não se defende aqui a participação exclusiva de indivíduos doentes como sujeitos dos testes de medicamentos.

Antes mesmo de progredir para as fases de avaliação em seres humanos, os testes clínicos devem ser precedidos de estudos experimentais in vitro e em animais, com vistas a esclarecer pontos importantes relacionados à sua eficácia e toxicidade potenciais. Mesmo

\footnotetext{
${ }^{5}$ FCM-UNICAMP, Glossário da Faculdade de Ciências Médicas da Unicamp, Centro de Pesquisas Clínicas (CPC). Disponível online em: https://www.fcm.unicamp.br/fcm/cpc-centro-de-pesquisa-clinica/pesquisaclinica/glossario Acesso em 06-06-2018

${ }^{6}$ BRASIL - MINISTÉRIO DA SAÚDE. Conselho Nacional de Saúde. Resolução n. 196 de 10 de outubro de 1996, Artigo II.2. Disponível online $<$ http://bvsms.saude.gov.br/bvs/saudelegis/cns/1996/res0196 1010 1996.html > Acesso em 06-06-2018

7 MITCHAM, C. (Ed.). Encyclopedia of science, technology, and ethics, Vols. 1, Farmington Hills, MI: Thomson/Gale, 2005, p. 194.
} 
após passar por essas fases pré-teste, os testes clínicos nunca são desprovidos de riscos, tanto para indivíduos saudáveis como para aqueles acometidos pelas doenças em estudo, devendo ser ponderados os riscos e os benefícios para os participantes dos testes.

Além disso, a tensão entre os benefícios para a sociedade e os riscos impostos aos participantes dos experimentos humanos é inevitável, ${ }^{8}$ dado que toda a pesquisa com seres humanos contrapõe dois valores básicos: a evolução livre da ciência ${ }^{9}$ e a proteção da saúde do indivíduo. A principal questão que surge desse embate é: até que ponto, e em quais circunstâncias, a sociedade pode expor alguns de seus membros a prejuízos com vistas a promover beneficios para um grupo de individuos, para a sociedade como um todo ou para as gerações futuras? ${ }^{10}$

A resposta a esse questionamento deve necessariamente passar por discussões envolvendo as diversas áreas do conhecimento humano, não podendo ficar restrita à classe médico-científica. É nessa linha de pensamento que o presente trabalho se propõe a desenvolver reflexões jurídicas, éticas e sociológicas acerca da experimentação humana.

No campo jurídico, pretende-se realizar uma retrospectiva histórica do tratamento da experimentação com seres humanos, acompanhada de uma análise da normativa e da jurisprudência internacionais sobre o assunto. Especial atenção será direcionada ao "Caso Médico", julgamento dos médicos que realizaram experimentos sem o consentimento das populações-alvo do regime nazista. Da mesma forma, será analisado em profundidade o Código de Nuremberg de 1947, marco inicial da regulação da experimentação humana, cuja promulgação foi impulsionada pela revelação dos experimentos nazistas.

Serão também analisados em detalhe uma série de documentos jurídicos inspirados pelo Código de Nuremberg, assim como a potencial instrumentalização dos direitos humanos na área médica. Com efeito, os valores e princípios inerentes aos direitos humanos têm assumido uma posição central nas sociedades modernas, penetrando todas as esferas de atuação humana, inclusive as ciências biomédicas.

Dessa forma, pretende-se investigar como o direito internacional trata a experimentação humana, e qual o seu papel na prevenção da realização de testes desumanos e no exame concreto das violações aos direitos dos participantes. De forma complementar,

\footnotetext{
${ }^{8}$ MITCHAM, C. (Ed.). Encyclopedia of science, technology, and ethics, Vols. 1, Farmington Hills, MI: Thomson/Gale, 2005, p. 194.

${ }^{9}$ Discussões a respeito de um conceito de "ciência livre de valores" como um valor cognitivo ou não cognitivo serão realizadas no capítulo 2.1.1.

${ }^{10}$ KATZ, Jay. Experimentation with Human Beings: The Authority of the Investigator, Subject, Professions, and State in the Human Experimentation Process. New York: Russell Sage Foundation, 1972, p. 1.
} 
o estudo comparativo do tratamento dado por diferentes sistemas jurídicos internacionais e nacionais mostra-se valioso para a compreensão do grau de impacto dos direitos humanos na regulação da experimentação humana.

Ainda sob um olhar jurídico, outras questões conexas à experimentação humana serão analisadas, dentre elas a relevância da soft law, tendo em vista que grande parte da normativa sobre o tema é proveniente de documentos não vinculantes, elaborados por associações e organizações internacionais, o que, à primeira vista, pode suscitar dúvidas quanto à eficácia de sua implementação.

No campo ético, questões específicas no âmbito da pesquisa médica serão analisadas sob o ponto de vista da bioética e de sua regulamentação nacional, regional e internacional. Especial atenção será dedicada ao consentimento informado, tendo em vista a grande incidência de problemas éticos que dele decorrem. Serão também realizadas análises acerca dos critérios universais ou locais do consentimento informado, da distinção entre terapia e pesquisa, da transparência quanto aos riscos e benefícios do experimento, da garantia de continuidade no tratamento e, finalmente, dos limites da mercantilização do corpo humano.

Uma série de documentos do campo da ética médica também serão examinados, em especial a Declaração de Helsinque de 1964, da Associação Médica Mundial (AMM) . Especial atenção será direcionada aos princípios fundamentais da bioética proclamados pelo paradigmático Belmont Report de 1978 ${ }^{11}$, a saber: (i) o respeito à autonomia da vontade; (ii) o princípio da beneficência; (iii) o princípio da não maleficência; (iv) e o princípio da justiça.

De forma complementar às análises jurídicas e éticas, são de grande valia para o presente estudo as reflexões filosóficas de autores como Immanuel Kant e Hans Jonas ${ }^{12}$, especialmente no tocante às concepções de autonomia da vontade e dignidade humana, e dos limites éticos e morais da utilização do homem para fins científicos. Embora o presente estudo não se proponha a desenvolver uma tese filosófica, as perspectivas da filosofia se mostram necessárias para o desenvolvimento do tema, especialmente no que diz respeito à

\footnotetext{
${ }^{11}$ UNITED STATES DEPARTMENT OF HEALTH AND HUMAN SERVICES - HHS, Belmont Report: Ethical Principles and Guidelines for the Protection of Human Subjects of Research, Report of the National Commission for the Protection of Human Subjects of Biomedical and Behavioural Research (OPRR Reports - NIH - PHS - HHS, April 18, 1979).

12 "Let us not forget that progress is an optional goal, not an unconditional commitment, and that its tempo in particular, compulsive as it may become, has nothing sacred about it. Let us also remember that a slower progress in the conquest of disease would not threaten society, grievous as it is to those who have to deplore that their particular disease be not yet conquered, but that society would indeed be threatened by the erosion of those moral values whose loss, possibly caused by too ruthless a pursuit of scientific progress, would make its most dazzling triumphs not worth having". Cf. JONAS, Hans. Philosophical reflections on experimenting with human subjects. Daedalus, the Journal of the American Academy of Arts and Sciences 1969; 98: 219-247.
} 
análise dos diversos interesses dos sujeitos envolvidos - paciente, médico, pesquisador, empresas, sociedade e classe médica.

Discussões sociológicas se fazem necessárias em decorrência da exportação dos testes de medicamentos a sociedades menos favorecidas, as quais não necessariamente se beneficiam com os experimentos nem têm acesso ao resultado final. Nesse sentido, são valiosas as contribuições de Ulrich Beck e Anthony Giddens ${ }^{13}$, notadamente suas análises pontuais sobre a "globalização de riscos", na qual se exportam riscos e prejuízos aos países em desenvolvimento, mantendo-se benefícios e lucro das atividades nos países desenvolvidos.

Assim, discussões jurídicas, filosóficas e sociológicas serão suscitadas em suas convergências e divergências, a fim de que se compreenda o papel do direito interacional na regulação da experimentação humana. Com esse objetivo, analisar-se-ão os marcos da experimentação humana e sua inserção nos movimentos de globalização (Capítulo 1), os principais dilemas éticos dos testes com seres humanos (Capítulo 2) e o tratamento jurídico dos testes com seres humanos na atualidade (Capítulos 3 e 4).

Por fim, buscar-se-á, a partir da presente tese, elaborar reflexões gerais sobre a o tratamento jurídico da experimentação humana (Capítulo 5) e promover as seguintes contribuições originais: (i) analisar a internacionalização da experimentação humana no contexto da globalização de riscos; (ii) trabalhar a relação entre bioética e direitos humanos; discutindo o potencial de universalidade da bioética da experimentação humana, (iii) realizar o estudo da regulamentação internacional, regional e nacional de testes de medicamentos, com o propósito de extrair os princípios e as regras mais relevantes para a proteção do participante socioeconomicamente vulnerável.

\footnotetext{
${ }^{13}$ BECK, Ulrich; GIDDENS, Anthony; LASH, Scott. Modernização reflexiva: política, tradição e estética na ordem social moderna. São Paulo: Editora da Universidade Estadual Paulista, 1997. GIDDENS, Anthony. Risk and Responsibility. Modern Law Review 62(1): 1-10, 1999. BECK, Ulrich. Risk Society: Towards a New Modernity. New Delhi: Sage. (Translated from the German Risikogesellschaft), 1986. BOHOLM, Åsa. The Cultural Nature of Risk: Can there bean Anthropology of Uncertainty?, vol. 68:2, june 2003 (pp. 159-178). SLOVIC, Paul. The Psychology of Risk, Psychology Colloquia, Paper 9, 2012. Disponível online em: http://fordham.bepress.com/psych_colloquia/9 Acesso em 06-06-2018
} 
investigadores devem especificar quais são os incentivos financeiros ${ }^{651}$ e os comitês de ética e órgãos reguladores devem zelar para que eles não configurem influência indevida para a participação, sendo que todo participante deve ser registrado em cadastro nacional com vistas a se evitar a participação concomitante em mais de um teste e, consequentemente, a interação medicamentosa ${ }^{652}$.

Devem ser estipuladas, já no protocolo de pesquisa, as previsões quanto à continuidade do acesso ao medicamento testado quando tal medicamento for considerado benéfico ao participante ${ }^{653}$.

No que concerne aos testes realizados no exterior, deve haver escrutínio por comitês de ética tanto no país de origem da instituição patrocinadora como no país receptor do experimento $^{654}$. Da mesma forma, deve ser prevista expressamente a jurisdição extraterritorial nos casos em que instituições e indivíduos sob a jurisdição de um Estado venham a realizar pesquisas no exterior ${ }^{655}$.

Além disso, o experimento deve ser projetado para envolver o menor grau de dor, sofrimento, medo e riscos para o sujeito ${ }^{656}$. Assim, quando existirem tratamentos de eficácia comprovada na literatura médica, fica proibido o duplo padrão ético, e, portanto, a administração de placebo ${ }^{657}$.

O presente trabalho ainda acrescentaria a essas disposições a constatação de que a presença de um terceiro imparcial para facilitar a compreensão dos indivíduos socioeconomicamente vulneráveis é essencial, não somente no momento da obtenção inicial do consentimento informado, mas durante diversos outros momentos do experimento. De fato, o sujeito deve ter a clara compreensão de seu direito de se retirar do teste a qualquer momento, tendo em vista ser o consentimento informado um processo contínuo, o qual se prolonga por toda a duração dos testes.

Em especial, deve-se solicitar a presença desse terceiro imparcial quando: (i) houver mudanças significativas nos testes que possam acrescentar riscos aos participantes; (ii)

\footnotetext{
${ }^{651}$ Sob os moldes do FDA Code of Federal Regulations (Estados Unidos), cf. nota 164.

${ }^{652}$ Sob os moldes do Projeto de Lei do Senado N. ${ }^{\circ}$ 7.082-A, de 2017 (Brasil), cf. nota 572.

${ }^{653}$ Sob os moldes do Regulamento 536/2014 (União Europeia), cf. nota 510, Resolução 196 de 1996 do CNS (Brasil), cf. nota 559, do Projeto de Lei do Senado N. ${ }^{\circ}$ 7.082-A, de 2017 (Brasil), cf. nota 572, e das Diretrizes ICMR (Índia). Cf. nota 544.

${ }^{654}$ Sob os moldes do Regulamento 2017/556 (União Europeia), cf. nota 516, e do Regulamento 536/2014 (União Europeia), cf. 517.

${ }^{655}$ Sob os moldes do Protocolo de Estrasburgo (Conselho da Europa), cf. nota 491.

${ }^{656}$ Sob os moldes do Regulamento 536/2014 (União Europeia), cf. nota 513.

${ }^{657}$ Sob os moldes da Resolução 466 de 2012 do CNS (Brasil), cf. nota 576, e do Projeto de Lei do Senado N. ${ }^{\circ}$ 7.082-A, de 2017 (Brasil), cf. nota 572.
} 
terminados os testes, na ocasião da realização de sessão de informação sobre os resultados obtidos e sobre a continuidade no acesso ao medicamento; e (iii) sempre que o participante socioeconomicamente vulnerável tiver dúvidas substanciais quanto às informações relevantes dos testes.

Ainda, esse terceiro imparcial deve ser escolhido com parcimônia e atenção, para que não atue de forma a influenciar indevidamente o participante a partir de outros interesses que não os do indivíduo. Por exemplo, líderes comunitários podem estar mais preocupados com a manutenção dos testes na região ou com a cura de doenças que afetam a população em questão, o que pode comprometer sua imparcialidade ao lidar com a participação de um indivíduo de sua comunidade. Jamais a decisão do grupo deve se sobrepor à decisão individual do participante. Prefere-se, dessa forma, a presença de profissionais acostumados a lidar com conflitos de interesses, os quais têm obrigação profissional de priorizarem os interesses do indivíduo em questão, tais como advogados ou assistentes sociais.

A presente tese sustenta que, nos casos excepcionais em que incompetentes especificamente para decidir sobre a participação sejam selecionados pelos investigadores, faz-se necessária a utilização de outras formas de explicação sobre as informações mais relevantes dos testes, as quais vão além da simples leitura do formulário de consentimento informado. Nesse sentido, os profissionais responsáveis pelo consentimento devem se valer de analogias, metáforas e outros mecanismos que possam facilitar a compreensão pelo sujeito, entre eles a utilização de vídeos explicativos e até encenações sobre os procedimentos futuros, deixando clara sua natureza experimental e a possibilidade que o participante tem de se retirar a qualquer momento.

O auxílio de um terceiro imparcial e de outros formatos de explicação sobre os procedimentos e interesses envolvidos nos testes contribuem para a equiparação entre o indivíduo socioeconomicamente vulnerável e o não vulnerável.

Ainda, no lugar da previsão que determina que devem constar do protocolo de pesquisa as condições para a continuidade no acesso ao medicamento ao fim dos testes, a presente tese defende a obrigatoriedade da presença de cláusula de garantia de continuidade no tratamento sempre que o medicamento for considerado benéfico ao participante. De fato, a garantia de que o tratamento não será interrompido previne a deterioração da saúde do participante e dá força à previsão já constante em praticamente todos os documentos jurídicos - internacionais e nacionais - de que os testes devem ter o condão de beneficiar os participantes vulneráveis. 
No entendimento deste trabalho, a atuação internacionalizada dos Estados por meio da elaboração de uma convenção no formato e com o conteúdo acima apontados seria de grande valia para a padronização global da proteção ao indivíduo socioeconomicamente vulnerável. Na ausência de uma convenção específica, normativas regionais e domésticas, assim como documentos da soft law, devem levar em consideração os avanços normativos acima descritos, a fim de que a proteção aos indivíduos vulneráveis permaneça avançando em todo o mundo.

Ainda no tocante à padronização da proteção do participante do experimento, faz-se mister refutar a utilização, pelos países-sede das farmacêuticas que patrocinam os testes, de documentos que oferecem proteção diminuída aos participantes no exterior quando comparada à proteção oferecida aos participantes sob sua jurisdição.

Condena-se, portanto a utilização das Diretrizes ICH - pelos Estados Unidos, Japão e países da Europa - como critério para análise da eticidade dos testes de medicamento realizados em países em desenvolvimento, quando do pedido de autorização de comercialização do medicamento. Isso porque internamente a proteção ao indivíduo vulnerável se dá via normas domésticas mais protetoras, enquanto que aos testes internacionais se aplicam diretrizes menos protetoras. Muito mais do que imperialismo ético - cujo efeito seria padronizar as regras conforme as tradições e elementos culturais ocidentais - essa proteção seletiva apenas aos nacionais dos países em desenvolvimento contribui para a eternização da exploração da vulnerabilidade de populações desfavorecidas em países em desenvolvimento.

Dessa forma, quando da análise da eticidade dos protocolos e dos testes realizados no exterior, defende-se a aplicação dos padrões mais elevados, em especial a aplicação do tratamento mais eficaz existente na literatura médica, como base de comparação para a substância administrada ao grupo de controle. Tal medida visa não somente à proteção dos participantes mas também à garantia da qualidade do medicamento que futuramente competirá com medicamentos que já estão no mercado. De fato, assim como definem as Diretrizes CIOMS, não há necessidade de se realizar testes para medicamentos contra determinada doença se a qualidade dos medicamentos testados será inferior aos medicamentos que já existem em outros países.

Por fim, há de se recordar que a bioética da experimentação humana foi criada como resposta às violações dos direitos dos participantes vulneráveis, os quais eram enquadrados em categorias sub-humanas e transformados em mero objeto de análise sem que seus direitos 
mínimos fossem respeitados. Da mesma forma, os direitos humanos tem como uma de suas características centrais a sua tendência a eleger pautas das minorias - quantitativas e qualitativas - e proteger os seus membros na medida da sua vulnerabilidade. Dessa forma, a bioética da experimentação humana que considera os direitos humanos como valores centrais não deve nunca perder de vista a motivação inicial que impulsionou a evolução das duas disciplinas, buscando sempre proteger os vulneráveis com afinco e precisão. 


\section{CONCLUSÃO}

Por meio desta conclusão serão apresentadas as considerações finais a respeito das principais discussões trabalhadas no presente estudo. Para a completa compreensão das reflexões gerais e das proposições da presente tese, mostra-se indispensável a leitura do capítulo precedente. ${ }^{658}$

A presente tese buscou compreender o tratamento dado pelo direito internacional à experimentação humana, em especial o impacto da bioética e dos direitos humanos na prevenção dos testes que violam os direitos dos participantes.

A experimentação humana, como instrumento essencial para a produção de conhecimento médico, é um empreendimento que naturalmente envolve interesses conflituosos das instituições e dos indivíduos envolvidos. No passado, enquanto a atividade era essencialmente promovida por entes públicos, os conflitos de interesses envolviam especialmente entidades governamentais, universidades públicas, médicos e participantes e, quando reportados, o que raramente ocorria, tais conflitos eram discutidos exclusivamente pela classe médica com base nos códigos de conduta da profissão.

No decorrer do século XX, com o fortalecimento do setor privado, a experimentação humana passou a ser elaborada, patrocinada e realizada por empresas, incidindo com maior intensidade os interesses comerciais das grandes multinacionais do setor farmacêutico. Além disso, a globalização acelerada das últimas décadas provocou a migração dos testes de medicamentos para países em desenvolvimento, o que acabou por suscitar novos conflitos de interesses, dessa feita envolvendo países-sede das grandes farmacêuticas e países receptores dos testes, além dos indivíduos e comunidades que participam dos testes.

Soma-se à internacionalização dos testes de medicamentos a grande visibilidade que a mídia internacional passou a dar às graves violações dos direitos dos participantes, a exemplo dos “Testes Rápidos de AZT" e dos "Experimentos de Kano", experimentos antiéticos patrocinados por instituições norteamericanas, cujos participantes foram indivíduos e comunidades socioeconomicamente vulneráveis de países em desenvolvimento. Tais fatores provocaram acaloradas discussões doutrinárias, além de maior demanda pela judicialização e melhor regulamentação da experimentação humana.

Da análise dos problemas mais relevantes da exportação dos testes de medicamentos e da seleção de indivíduos socioeconomicamente vulneráveis, foi possível eleger cinco temáticas que merecem destaque: (i) a definição de critérios mínimos para o consentimento

${ }^{658}$ Cf. capítulo 5 . 
livre e informado; (ii) a obrigatoriedade do aporte de benefícios aos participantes; (iii) a continuidade do acesso ao medicamento experimental ao fim dos testes; (iv) a proibição ao duplo padrão ético e ao uso de placebo em grupos de controle; e (v) a proibição ou a restrição da remuneração pela participação.

Em primeiro lugar, o termo de consentimento informado é um dos principais mecanismos de proteção ao participante e de auxílio aos pesquisadores na verificação da participação livre e informada. Para tal verificação, é necessária a análise da intenção do indivíduo de participar do teste de medicamento, com ênfase na compreensão da diferenciação entre terapia e pesquisa, isto é, no entendimento de que é ministrada droga cuja eficácia não foi comprovada e sobre a qual não existe literatura elaborada.

Da mesma forma, é necessário verificar a competência do indivíduo para compreender as informações mais relevantes sobre os procedimentos, em especial os riscos e benefícios previstos e os interesses de todos os envolvidos no experimento. A decisão, para ser autônoma, também deve ser tomada sem que incida nenhuma forma de controle externo, em especial a persuasão e a manipulação.

Somente a partir da análise da intenção, da compreensão e do controle no ato de se registrar como participante é possível verificar se o indivíduo é competente especificamente para consentir com a participação. Na dúvida, o investigador responsável pela análise deve impedir a participação do indivíduo no experimento. Reitera-se, pois, o pensamento de Hans Jonas, segundo o qual o progresso das ciências médicas é uma meta opcional e não um compromisso incondicional da humanidade, uma vez que o desenvolvimento lento da cura de determinada doença não se mostra per se uma ameaça à sociedade; em contrapartida, o grande perigo reside no desrespeito aos direitos mínimos dos indivíduos causado pela busca impiedosa do progresso científico. ${ }^{659}$

Cada sistema jurídico nacional tem seus critérios de verificação da competência específica para decidir sobre participação. Em alguns países os critérios são mais numerosos e elaborados, como nos Estados Unidos; em outros países, entre eles o Brasil, os critérios são mais enxutos, ficando a cargo do investigador a forma pela qual o participante é questionado com vistas a compreender o nível de sua vulnerabilidade. ${ }^{660}$

Em segundo lugar, faz-se mister compreender que a crescente exportação dos testes de medicamentos dos países desenvolvidos para os países em desenvolvimento não veio

\footnotetext{
659 JONAS, Hans. Philosophical reflections on experimenting with human subjects. Daedalus, the Journal of the American Academy of Arts and Sciences 1969; 98: 219-247.

${ }^{660}$ Cf. subcapítulos 4.1. e 4.4.
} 
acompanhada de uma maior atenção às necessidades de saúde pública desses últimos. Assim, a grande maioria dos recursos investidos nos experimentos destina-se ao diagnóstico e à cura de doenças que afetam apenas a população dos países mais ricos, naquilo que a OMS denomina “Desequilíbrio 10/90", isto é, 90\% dos investimentos destinam-se às doenças que afetam $10 \%$ da população mundial. ${ }^{661}$

Frente à excessiva utilização de indivíduos socioeconomicamente vulneráveis de países em desenvolvimento em testes que raramente visam a produzir medicamentos para a população pesquisada, diversos documentos internacionais passaram a defender que sua utilização só é justificável quando, apesar dos riscos, os testes tiverem o condão de oferecerlhes benefícios. Essa regra define um conteúdo mais específico aos princípios da beneficência e da justiça, os quais constituem a base doutrinária para a bioética da experimentação humana, ao lado dos princípios da autonomia e da não maleficência.

Assim, já na elaboração do protocolo de pesquisa, na sua análise por um comitê de ética e, também, durante a realização dos procedimentos, deve-se focar nos potenciais benefícios para os participantes socioeconomicamente vulneráveis.

Em terceiro lugar, uma temática que ganhou relevância foi a necessidade de se garantir, ao fim dos testes e quando seus resultados são considerados positivos, a continuidade do acesso ao medicamento testado para que o indivíduo possa continuar desfrutando do tratamento experimental. Isso porque, ao cabo dos testes, os resultados são encaminhados à entidade reguladora do país-sede da patrocinadora ou do país onde se pretende comercializar o produto e, na maioria dos casos, o participante perde o acesso ao medicamento, o que pode comprometer ainda mais a sua saúde. No Brasil, por exemplo, a judicialização de casos de participantes de testes que demandam fornecimento gratuito do novo medicamento ao governo vem causando graves consequências para o erário público e para a divisão orçamentária no âmbito da saúde pública. ${ }^{662}$

\footnotetext{
${ }^{661}$ World Health Organization - WHO, The 10/90 report on health research, 1999. Geneva: Global Forum for Health Research; 1999; World Health Organization - WHO, Bulletin of the World Health Organization Volume 86, Number 8, August 2008, 577-656. Disponível online em: <http://www.who.int/bulletin/volumes/86/8/08051110/en/> Acesso em 06-06-2018; World Health Organization - WHO, Investing in Health Research and Development: Report of the Ad Hoc Committee on Health Research Relating to Future Intervention Options, WHO, Geneva, Switzerland, 1996. Disponível online em: < http://apps.who.int/iris/bitstream/10665/63024/1/TDR_Gen_96.1_pp1-34.pdf > Acesso em 06-06-2018 ${ }^{662}$ PETRYNA, Adriana. When Experiments Travel: Clinical Trials and the Global Search for Human Subjects, Princeton, Princeton University Press, 2009, p. 184-185.
} 
Por isso, é necessário que, no momento da elaboração do protocolo de pesquisa e de sua análise pelo comitê de ética, sejam incorporadas cláusulas que garantam o acesso ao tratamento experimental pelo participante doente.

Em quarto lugar, a discussão mais polêmica da atualidade da experimentação humana tem sido a proibição ao duplo padrão ético a depender da localização geográfica dos testes, em especial a proibição do uso de placebo quando existam outros tratamentos de eficácia comprovada na literatura médica ou no país-sede do patrocinador. A maioria dos documentos internacionais proíbe a utilização de placebo e da não intervenção quando existir outro tratamento eficaz. Contudo, a doutrina, a normativa e a prática médica se dividem quanto à interpretação desse comando, em especial quanto à aplicação do padrão de tratamento local ou universal.

Sob o ponto de vista da proteção do socioeconomicamente vulnerável de países em desenvolvimento, deve-se terminantemente proibir o duplo padrão ético, tratando-se de forma igualitária membros do grupo de controle, independentemente de sua localização geográfica, nos seguintes termos: caso não exista tratamento eficaz na literatura médica, fica permitido o uso do placebo; quando tal tratamento existir, independentemente da sua disponibilidade no país receptor do experimento, tanto o uso do placebo quanto a não intervenção devem ser proibidos.

Somente assim é possível corrigir a perversa realidade da transferência para países em desenvolvimento de testes que, por serem consideradas antiéticas, jamais poderiam ocorrer no país-sede do patrocinador da pesquisa.

Atualmente, muitos experimentos que visam a desenvolver um determinado medicamento ocorrem concomitantemente em diversos países. Especialmente nesse contexto, o tratamento desigual dado aos grupos de controle não pode ser aceito, sob pena de se legitimar a discriminação socioeconômica e de se perpetuar as diferenças entre populações de países desenvolvidos e de países em desenvolvimento. Além disso, a proibição do duplo padrão ético proporciona maior segurança aos medicamentos que posteriormente serão comercializados nos países desenvolvidos, pois assim garante-se que o novo medicamento seja comparado a tratamentos já existentes no mercado desses países e não a placebos ou medicamentos de qualidade inferior.

Em quinto lugar, chama atenção a questão da remuneração do participante socioeconomicamente vulnerável. Isso porque a busca por compensação financeira é uma das motivações que levam indivíduos a se registrarem em testes de medicamentos e vacinas, adicionalmente à busca por acesso a tratamentos e cuidados médicos mais sofisticados - 
mesmo que de natureza experimental -, do sentimento de obrigação moral e do altruísmo profissional e social.

Em geral, quando as atividades relacionam-se à evolução da saúde pública, incentivase a participação gratuita dos indivíduos, inclusive proibindo-se o lucro, como, por exemplo, no caso da doação de sangue e de órgãos. Por isso, defende-se a proibição da remuneração ao participante de testes de medicamento, com vistas a coibir a influência indevida nas modalidades persuasão ou manipulação, as quais podem minar a competência do indivíduo de agir em defesa de seus melhores interesses. O combate à superexploração de indivíduos e populações vulneráveis em sede de testes de medicamentos testes passa pela garantia de que o participante esteja o mais próximo possível do que Paul Ricoeur chama de "parceiro voluntário da experimentação humana", 663 evitando-se a mercantilização de seu corpo e de seu bem-estar.

Todavia, observa-se recentemente uma tendência no sentido permitir a remuneração pela participação em testes de medicamentos, o que obriga especialistas e investigadores a discutir os limites da busca pelo interesse econômico em detrimento do bem-estar e da integridade física do indivíduo. Nos países em que a remuneração já é permitida por lei, defende-se que os comitês de ética refutem valores exorbitantes, considerando-os influência indevida, com vistas a evitar que o indivíduo se "profissionalize" como "cobaia humana". Além disso, a fim de impedir a interação medicamentosa, devem ser registrados em cadastro nacional os dados do indivíduo e todos os testes dos quais tenha participado.

Essas são as questões mais polêmicas e relevantes da experimentação humana atual sob o viés da proteção do participante socioeconomicamente vulnerável, as quais não necessariamente são reguladas da mesma maneira pelos Estados. De fato, cada sistema jurídico trabalha a experimentação humana à sua maneira, sendo possível observar aspectos positivos e negativos no tratamento dado por cada país ou grupo de países ao sujeito socioeconomicamente vulnerável em sede de testes de medicamentos.

No âmbito europeu, é elogiável a elaboração de documentos de aplicação obrigatória, tanto pelo Conselho da Europa quando pela União Europeia, os quais dedicam atenção à internacionalização dos testes de medicamentos e à exploração das populações vulneráveis em benefício da evolução da medicina nos países desenvolvidos. Espera-se, entretanto, uma aplicação mais contundente das referidas normas por meio não apenas da jurisprudência da Corte Europeia de Direitos Humanos como também da regulação pelos Estados com base

${ }^{663}$ RICOEUR, P. Les trois niveaux du jugement médical. Esprit, Paris, décembre, 1996, p. 28. 
nas diretrizes da União Europeia. Aliás, a União Europeia tem surpreendido positivamente ao regulamentar os testes de medicamentos com participantes vulneráveis no exterior, sob os argumentos da garantia da qualidade dos medicamentos que serão comercializados na Europa e do avanço da pauta dos direitos humanos dos participantes.

No que concerne aos Estados Unidos, refuta-se a mudança recente em sua legislação que substituiu a Declaração de Helsinque pelas Diretrizes ICH como padrão para análise, em sede de pedido de comercialização, de testes ocorridos no exterior. Tal atitude, adotada em defesa do duplo padrão ético, é possivelmente aquela que mais prejudicou a proteção do participante socioeconomicamente vulnerável dos testes de medicamentos em países em desenvolvimento.

A Índia, país que se constitui o principal destino da exportação dos testes de medicamentos, permite expressamente o duplo padrão ético. Da análise da prática da experimentação humana na Índia, conclui-se que o país vem sendo conivente com a exploração de sua população vulnerável, rendendo-se a interesses comerciais das grandes empresas farmacêuticas.

Finalmente, o Brasil, que por muitos anos foi elogiado em razão de sua normativa sofisticada, passou recentemente a revogar antigas proteções importantes aos indivíduos vulneráveis e, atualmente, protege especificamente apenas uma parcela dos socioeconomicamente vulneráveis - os indígenas e os analfabetos -, desconsiderando outros indivíduos incompetentes para decidir sobre sua participação nas pesquisas.

Em geral, da análise do tratamento dado aos testes de medicamentos por sistemas jurídicos nacionais e regionais conclui-se que há maior proteção ao sujeito socioeconomicamente vulnerável de países desenvolvidos do que ao sujeito em situação análoga proveniente de países em desenvolvimento. As principais razões para tal discrepância são as seguintes: (i) a legislação dos países em desenvolvimento, receptores dos testes, é volátil, contando com evoluções e retrocessos no que diz respeito à proteção do indivíduo socioeconomicamente vulnerável; (ii) nos países em desenvolvimento, mesmo que a legislação disponha sobre proteções aos participantes socioeconomicamente vulnerável, a regulação da experimentação humana é falha, padecendo de vícios como corrupção e negligência; (iii) os países desenvolvidos, apesar de contarem com uma legislação mais protetora do participante socioeconomicamente vulnerável, raramente se utilizam de sua jurisdição extraterritorial, deixando de aplicar tais proteções aos participantes de testes no exterior, mesmo quando o patrocinador é uma empresa nacional; e (iv) as entidades reguladoras dos países desenvolvidos, em sede de análise de pedido de autorização para 
comercialização de medicamento testado no exterior, aplicam critérios menos protetores aos participantes quando comparados aos critérios aplicados aos participantes de testes que ocorrem sob sua jurisdição.

Internacionalmente, diversos documentos jurídicos já trataram da experimentação humana. A Associação Médica Mundial (AMM) e as agências da Organização das Nações Unidas (ONU), em especial a UNESCO e a OMS, destacam-se na tarefa de elaborar a normativa internacional no assunto.

No que concerne ao seu conteúdo, a bioética internacional da experimentação humana é composta por normas riquíssimas, as quais dispõem sobre a proteção do participante socioeconomicamente vulnerável de países em desenvolvimento. Nesse sentido, destacam-se a Declaração da UNESCO de 2005 (UNESCO), a Declaração de Helsinque de 1964 (Associação Médica Mundial - AMM) e as Diretrizes Éticas Internacionais para a Pesquisa Biomédica Envolvendo Seres Humanos de 1982 (CIOMS/OMS), as quais são constantemente atualizadas de acordo com as discussões da atualidade.

Tais documentos são utilizados como base por algumas legislações nacionais, pelos comitês de ética e pela doutrina especializada no mundo todo, contando com um alcance relevante em uma pluralidade de sociedades cujas raízes culturais e sociais são diversas.

No que tange à sua natureza, a bioética internacional da experimentação humana é composta majoritariamente por documentos da soft law, não contando com tratados de aplicação obrigatória nem com mecanismos de controle da atuação dos Estados. Assim, o conjunto de documentos da bioética internacional acaba incidindo mais no campo da política e da moral.

Assim, a verdadeira força normativa da normativa internacional sobre a bioética não vem de sua forma, mas sim de seu conteúdo, de seu alcance e da repetição constante de seus dispositivos na legislação interna dos Estados. Tal repetição, além de inspirar a evolução da bioética nacional da experimentação humana, demonstra a existência de um costume internacional que prioriza o indivíduo frente a outros interesses e demanda a proteção do participante socioeconomicamente vulnerável em sede de experimentação humana.

Portanto, pode-se afirmar que esses diversos documentos dão grande visibilidade e inscrevem a experimentação humana na pauta das discussões internacionais. Contudo, a harmonização da proteção mínima aos indivíduos socioeconomicamente vulneráveis, independentemente de sua origem, ainda é uma realidade distante. 
Para lidar com os riscos da internacionalização progressiva dos testes de medicamentos para países em desenvolvimento, em especial a exploração de indivíduos e comunidades vulneráveis, fazem-se necessárias ações mais contundentes por parte dos Estados, as quais podem se dar por meio da elaboração de uma convenção específica ou por meio da elaboração e aprimoramento de regras mais protetoras do participante, algumas delas já existentes nas normativas nacionais e regionais.

A presente tese entende que a adoção de critérios de proteção com base em normas de origem ocidental e de inspiração liberal por países que não compartilham das mesmas raízes e traços culturais não resulta necessariamente em imperialismo ético, notadamente na medida em que o Estado adotante esteja de acordo com o seu conteúdo. Entretanto, o presente trabalho defende a adoção das referidas normas apenas quando elas tiverem o condão de proteger o socioeconomicamente vulnerável de países em desenvolvimento da mesma forma que protegem o indivíduo em condições análogas em países desenvolvidos; caso contrário, defende-se a aplicação da norma local.

Essa questão da adoção de normas de origem estrangeira pode ser discutida com base na célebre metáfora do filósofo Paul Ricoeur sobre a obra de arte. ${ }^{664}$ Segundo Ricoeur, uma obra-prima é elaborada pelo artista em determinado contexto e segundo certos objetivos, mas, quando se torna verdadeiramente importante, passa a influenciar novos admiradores em outros contextos, os quais a adotam e a reinterpretam de acordo com suas próprias preocupações e visões de mundo, sem que a obra original perca seu valor. Seguindo essa mesma lógica, a adoção de normas da bioética por um Estado que não participou de sua elaboração não deve, a priori, ser vista com estranheza ou indignação, mas sim como uma apropriação que pode ser benéfica para o participante.

A elaboração legislativa nada mais é do que uma obra humana, passível, portanto, de modificação por outros atores da sociedade internacional. Frente aos riscos do empreendimento dos testes de medicamentos, os quais são exportados aos países desfavorecidos afetando populações mais vulneráveis, o presente trabalho conclui que, além de se reinterpretar as normas da bioética da experimentação humana, há de se reinterpretar a própria relação entre a sociedade e desenvolvimento técnico-científico, promovendo a celebração de um novo contrato que estipule como um dos objetivos centrais da evolução científica a redução da vulnerabilidade.

${ }^{664}$ GÉRARD, Philippe, L'esprit des droits. Philosophie des droits de l'homme, Bruxelles, St Louis, 2007, p. 158. 
De fato, assim como explicitado no presente trabalho, ${ }^{665}$ a ciência não é neutra, incidindo sobre ela atores e intenções diversos, os quais influenciam sobremaneira sua evolução ao ditar suas prioridades e objetivos. Reitera-se, portanto, que um desses objetivos deve ser a diminuição da vulnerabilidade econômica e social, por meio do combate à pobreza, à marginalização e à discriminação.

Por fim, um dos temas recorrentes no presente trabalho relacionou-se ao uso da tecnologia digital na área médica. Mais especificamente, a presente tese citou o desenvolvimento de plataformas online para registro dos testes de medicamento.

De fato, diversos Estados têm implementado plataformas online para o armazenamento obrigatório dos registros dos testes de medicamentos realizados em sua jurisdição. Além dessas iniciativas nacionais, a Organização Mundial da Saúde desenvolveu uma Plataforma Internacional para Registros de Testes Clínicos (WHO International Clinical Trials Registry Platform), ${ }^{666}$ que visa a trazer maior publicidade e transparência aos experimentos ao reunir dados de entidades de registros de diversas localidades. A plataforma da OMS, inaugurada em 2004, já se encontra em funcionamento e tem se mostrado um instrumento para a melhor compreensão da experimentação humana global, notadamente por harmonizar as buscas por testes concluídos.

Sob um primeiro olhar, tais iniciativas são benéficas, mas é importante considerar que atualmente a obrigatoriedade de registro somente é válida para os testes que foram concluídos e que tiveram resultados positivos, tendo em vista que a preocupação inaugural para adoção de registros eletrônicos relacionou-se à segurança dos medicamentos prontos para serem comercializados. Essa publicação seletiva dos testes que obtiveram resultados positivos é algo a ser combatido, pois não impede a realização de novos testes sob os moldes daqueles que deixaram de ser publicados, os quais podem resultar em ainda mais riscos aos participantes.

Exemplo claro da importância da publicação de testes que não foram bem-sucedidos se deu nos "Experimentos com Lorcainide", cujo objetivo era tratar indivíduos com problemas cardíacos. Após os testes, a droga se mostrou oito vezes mais letal do que o tratamento padrão administrado ao grupo de controle, mas a publicação do referido teste só veio a ocorrer dez anos depois. Estima-se que, nesse período de 10 anos, mais de 100 mil pessoas vieram a falecer, seja em decorrência da participação em outros testes fatais com

${ }^{665}$ Cf. subcapílo 2.1.1.

${ }^{666}$ WHO International Clinical Trials Registry Platform. Disponível online em: $<\mathrm{http}: / /$ apps.who.int/trialsearch/Default.aspx $>$ Acesso em 06-06-2018 
drogas similares, seja por fazerem uso de drogas análogas que já se encontravam no mercado. ${ }^{667}$ Tais vidas poderiam ter sido poupadas caso o registro dos testes com lorcainide tivesse sido realizado.

Diante disso, diversas ONGs da área da saúde se reuniram para lançar, em 2013, a campanha internacional em prol da plataforma AllTrials, que conta com a assinatura de 735 instituições e mais de 90 mil pessoas, tendo como slogan "todos os testes registrados, todos os resultados reportados". ${ }^{668}$ A iniciativa é interessante por defender o registro não somente dos testes de medicamento que obtiveram resultados positivos, mas também daqueles que obtiveram resultados negativos, além dos que não foram aprovados e dos que tiveram seu processo interrompido.

Esse movimento a favor da publicação de todos os testes de medicamentos entende que a publicação não seletiva favorece a proteção do participante e do consumidor final, especialmente porque: (i) os sujeitos passam a ter a comprovação, para além do termo de consentimento informado, de que participaram dos testes; (ii) economizam-se tempo e investimentos e protege-se a saúde dos participantes que potencialmente participariam de testes similares aos que não obtiveram resultados satisfatórios; (iii) em caso de resultados que demonstram alto risco para a saúde humana, drogas similares às testadas que já estejam no mercado podem ser reavaliadas.

Adicionalmente à questão do registro eletrônico dos testes, outros aspectos relativos à utilização da tecnologia digital em sede de experimentação humana merecem ser analisados de maneira aprofundada, o que não foi possível realizar em razão das limitações metodológicas do presente estudo. Ciente da importância das novas questões suscitadas pela evolução tecnológica, a presente tese deixa em aberto a relevante discussão sobre o impacto do desenvolvimento da tecnologia digital no empreendimento da experimentação humana, encorajando a comunidade acadêmica a se debruçar sobre o tema a fím de melhor compreender os dilemas éticos, filosóficos e jurídicos a ele relacionados.

${ }^{667}$ LANE, Síle. The hidden side of clinical trials, TED Talks, Sep 28, 2016.

Disponível online em: $<$ https://www.youtube.com/watch?v=-RXrGLolgEc $>$ Acesso em 06-06-2018

668 ALLTRIALS, What all trials is calling for?, AllTrials website. Disponível online em: http://www.alltrials.net/find-out-more/all-trials/ Acesso em 06-06-2018 


\section{REFERÊNCIAS}

AITH, F.; CUNHA, A.; CASTELLARO, F.; SOARES, D.; DALLARI, S. Regulação de medicamentos no Brasil: desafios no contexto do mundo globalizado. Centro de Estudos e Pesquisas de Direito Sanitário (CEPEDISA). Regulação de medicamentos no mundo globalizado. Org. Fernando Aith, Sueli Gandolfi Dallari. - São Paulo: Cepedisa, 2014.

ALBUQUERQUE, A., BARBOZA, H. H. Remuneração dos participantes de pesquisas clínicas: considerações à luz da Constituição. Rev. bioét. (Impr.). 2016; 24 (1): 29-36. Disponível online em: $<$ http://dx.doi.org/10.1590/1983-80422016241103> Acesso em 0606-2018

ALMEIDA, José Luiz Telles de. Respeito à Autonomia do Paciente e Consentimento Livre e Esclarecido: Uma Abordagem Principialista da Relação Médico-Paciente. Tese de doutorado em Ciências da Saú

ALVES, L.C.A. Ética e psiquiatria. Conselho Regional de Medicina do Estado de São Paulo, 2007.de, Escola Nacional de Saúde Pública, Fundação Osvaldo Cruz, Rio de Janeiro, 1999

ANNAS, George J. Standard of Care: The Law of American Bioethics, Oxford University Press, New York, 291 p., 1993.

ANNAS, George J., GRODIN, Michael A., Medical Ethics and Human Rights: Legacies of Nuremberg, 3 HOFSTRA L. \& POL'Y SYMP. 111, 1999, p. 121.

APPELBAUM, P. S., GRISSO, T., The MacArthur Competence Assessment Tool for Clinical Research (MacCAT-CR). Sarasota, FL: Professional Resource Press; 2001.

ARAUJO, Diego Vinicius Pacheco de. A caracterização do analfabetismo funcional em usuários do Hospital das Clínicas da Faculdade de Medicina da Universidade de São Paulo: recomendações para a redação do termo de consentimento livre e esclarecido. Dissertação (Mestrado) - Escola de Enfermagem da Universidade de São Paulo, São Paulo, 2009. p. 8;

ARENDT, Hannah, A vida do espírito. Rio de Janeiro: Relume Dumará, 1992.

AZAMBUJA, Letícia Erig Osório de; GARRAFA, Volnei. A teoria da moralidade comum na obra de Beauchamp e Childress. Rev. Bioét., Brasília , v. 23, n. 3, p. 634-

644, Dec. 2015, p. 634. Disponível online em:

http://www.scielo.br/scielo.php?script $=$ sci arttext\&pid $=\mathrm{S} 1983-$

$\underline{80422015000300634 \& \operatorname{lng}=\text { en\&nrm=iso Acesso em 06-06-2018 }}$

BASSIOUNI, Cherif M., International Criminal Law, Volume 1: Sources, Subjects and Contents, Third Edition, Brill Nijhoff, 2008. 
BASSIOUNI, M. Cheriff, BAFFES, Thomas G., EVRARD, John T. An Appraisal of Human Experimentation in International Law and Practice: The Need for International Regulation of Human Experimentation, 72 J. Crim. L. \& Criminology 1597 (1981). Disponível online em: $<\underline{\text { http://scholarlycommons.law.northwestern.edu/jclc/vol72/iss4/20> }}$ Acesso em 06-06-2018

BBC, Horizon: The Human Laboratory, written and produced by Deborah Cadbury, London, BBC, 1995.

BBC, The Drug Trial: Emergency at the Hospital Documentary 2017, 14 February 2017. Disponível online em: http://www.bbc.co.uk/programmes/b08g8np3 Acesso em 06-062018

BEAUCHAMP, Tom L., CHILDRESS, James F., Principles of Biomedical Ethics, Seventh Edition, New York: Oxford University Press, 2013.

BECK, Ulrich; GIDDENS, Anthony; LASH, Scott. Modernização reflexiva: politica, tradição e estética na ordem social moderna. São Paulo: Editora da Universidade Estadual Paulista, 1997

BECK, Ulrich. Risk Society: Towards a New Modernity. New Delhi: Sage. (Translated from the German Risikogesellschaft), 1986.

BECK, Ulrich. Sociedade de Risco: rumo a uma outra modernidade. Trad. Sebastião Nascimento, Rio de Janeiro: Editora 34, 1994.

BEECHER, Henry K. Research and the Individual: Human Studies. Boston: Little, Brown, 1970.

BEECHER, Henry K., Ethics and clinical research. New England Journal of Medicine, 274:1354-1360, 1966.

BENTLEY, J. P., THACKER, P. G., The influence of risk and monetary payment on the research participation decision making process. Journal of Medical Ethics, vol. 30, p. $293-$ 298, 2004. Disponível online em:

https://www.ncbi.nlm.nih.gov/pmc/articles/PMC1733848/pdf/v030p00293.pdf Acesso em $\underline{06-06-2018}$

BOBBIO, Norberto. Direito e Estado no pensamento de Emanuel Kant. Brasilia: Ed. UnB, 1969 ,

BOHOLM, Åsa. The Cultural Nature of Risk: Can there bean Anthropology of Uncertainty?, vol. 68:2, june 2003 (pp. 159-178).

BRASIL. Plataforma Brasil. Disponível online em: www.saude.gov.br/plataformabrasil Acesso em 06-06-2018

BRASIL - MINISTÉRIO DA SAÚDE. Conselho Nacional de Saúde. Resolução n. 196 de 10 de outubro de 1996. Disponível online em: 
$<\underline{\text { http://bvsms.saude.gov.br/bvs/saudelegis/cns/1996/res0196 } 10 \quad 10 \quad 1996 . h t m l}>$ Acesso em 06-06-2018

BRASIL - MINISTÉRIO DA SAÚDE. Conselho Nacional de Saúde. Resolução n. 466 de 12 de dezembro de 2012. Disponível online em:

$<$ http://bvsms.saude.gov.br/bvs/saudelegis/cns/2013/res0466 12_12 2012.html $>$ Acesso em 06-06-2018

BROWNLIE, Ian. International law at the fiftieth anniversary of the United Nations general course on public international law, R.C.A.D.I., 1995, vol. 255.

BULL, Hedley. The Anarchical Society: a Study of Order in World Politics, London: Macmillan, 1977.

CALMAN, Kenneth. Conducting research ethically in developing countries, Drug Discov Today 7 (23), 1155-1159. 2002 Dec 01.

CÂMARA DOS DEPUTADOS, Projeto de Lei N. ${ }^{\circ}$ 7.082-A, de 2017 (Do Senado Federal). PLS n $^{\circ}$ 200/2015 Ofício no 124/2017 - SF. Disponível online em:

http://www.camara.gov.br/proposicoesWeb/prop mostrarintegra?codteor=1655573\&filena

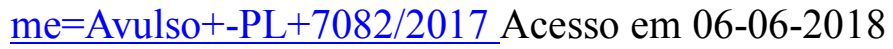

CAPLAN, Arthur. Health disparities and clinical trial recruitment: Is there a duty to tweet?, Journal Plo Biology, Published: March 1, 2017. Disponível online em:

http://dx.doi.org/10.1371/journal.pbio.2002040 Acesso em 06-06-2018

CAPRON, Alexander M., Experimentation with Human Beings: Light or Only Shadows?, Yale Journal of Health Policy, Law, and Ethics, Vol. 6: Iss. 2, Article 8., 2013, p. 433. Disponível online em:

http://digitalcommons.law.yale.edu/cgi/viewcontent.cgi?article $=1138 \&$ context $=y j h p l e$ Acesso em 06-06-2018

CARLSON, Robert V, KENNETH, M Boyd, DAVID, J Webb. The Revision of the Declaration of Helsinki: Past, Present and Future. British Journal of Clinical Pharmacology 57.6, 2004, p. 695-713

CHADWICK, Ruth (ed.). Encyclopedia of Applied Ethics, Cardiff: Academic Press, Vol. 1, 2nd Edition, 2012.

CHADWICK, Ruth (ed.). Encyclopedia of Applied Ethics, Cardiff: Academic Press, Vol. 3, 2nd Edition, 2012, p. 268.

CLAPHAM, Andrew; JERBI, Scott. Categories of Corporate Complicity in Human Rights Abuses. Hastings International and Comparative Law Review 24.3 (2001): 339-350.

CLAPHAM, Andrew. Extending International Criminal Law beyond the Individual to Corporations and Armed Opposition Groups. Journal of International Criminal Justice 6.5 (2008): 899-926

CONGRESSO BRASILEIRO DE BIOÉTICA, Carta de Brasília. Documento Resultante 
do Fórum Nacional Declaração de Helsinki: Perspectivas da Sociedade Brasileira. Brasília: Anis - Instituto de Bioética Direitos Humanos e Gênero/ Conselho Federal de Medicina/Fundação Oswaldo Cruz, 2000. Disponível online em:

$<\mathrm{http}$ //www.ip.usp.br/portal/images/stories/Carta_de_Braslia_sobre_Projetos_Multicntrico s_de_Pesquisa_Clnica_e_de_Defesa_do_Sistema_CEP-CONË.pdf $>$ Acesso em 06-062018

CONSELHO FEDERAL DE MEDICINA - CRM. Iniciação à Bioética. 1 ed. Conselho Federal de Medicina: Brasília (DF); pp. 302, 1998.

COOK, Michael. World Medical Association to revise Hippocratic Oath, BioEdge Bioethics News From Around the World, 20 Feb 2016. Disponível online em: $<$ https://www.bioedge.org/bioethics/world-medical-association-to-revise-hippocraticoath/11760> Acesso em 06-06-2018

CORTE INTERAMERICANA DE DIREITOS HUMANOS, Opinião em Separado do Juiz Cançado Trindade, em voto na Corte Interamericana de Direitos Humanos, no caso de "Desaparecimento forçado dos meninos de rua da Guatemala". Disponível online em: http://www.corteidh.or.cr/docs/casos/articulos/seriec_32_esp.pdf Acesso em 06-06-2018

COUNCIL FOR INTERNATIONAL ORGANIZATIONS OF MEDICAL SCIENCES CIOMS, International Ethical Guidelines for Health-related Research Involving Humans, Fourth Edition, Geneva, 2016. Disponível online em: $<$ http://cioms.ch/ethical-guidelines2016/WEB-CIOMS-EthicalGuidelines.pdf $>$ Acesso em 06-06-2018

COUNCIL OF EUROPE, Guide for Research Ethics, Committee Members Steering Committee on Bioethics, April 2012, p. 49. Disponível online em:

https://rm.coe.int/CoERMPublicCommonSearchServices/DisplayDCTMContent?documen

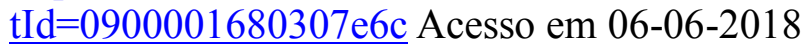

COUNCIL OF EUROPE. Convention for the Protection of Human Rights and Dignity of the Human Being with regard to the Application of Biology and Medicine: Convention on Human Rights and Biomedicine, European Treaty Series - No. 164, Oviedo, 4.IV.1997.

CUMMINGS, Steven R., ROWBOTHAM, Michael C. Electronic Informed Consent and Internet-Based Trials, The New England Journal of Medicine, p. 859-861, 2017.

CUNHA, Thiago Rocha da. Pagamento a Sujeito de Pesquisa na Perspectiva Ética de Membros do Sistema CEP/CONEP, Dissertação de Mestrado sob orientação de Cláudio Fortes Garcia Lorenzo, Universidade de Brasília, 2010.

DE SCHUTTER, Olivier. Extraterritorial jurisdiction as a tool for improving the human rights accountability of transnational corporations. Unpublished serminar paper in collaboration with the Office of the UN High Commissioner of Human Rights, Dec. 2006, disponível online em: http://198.170.85.29/Olivier-de-Schutter-report-for-SRSGreextraterritorial-jurisdiction-Dec-2006.pdf Acesso em 06-06-2018

DEGRAZIA, David, GROMAN, Michelle, LEE, Lisa M. Defining the Boundaries of a Right to Adequate Protection: A New Lens on Pediatric Research Ethics. Journal of Medicine and Philosophy, 42: 132-153, 2017. Disponível online em: < 
https://www.ncbi.nlm.nih.gov/pubmed/28186557> Acesso em 06-06-2018

DESCARTES, René. Discurso do Método. São Paulo. Os pensadores, Nova Cultural, 1996, p. 116.

DI GIULIO, Gabriela Marques. Construindo o diálogo para produzir conhecimento e enfrentar situações de risco: uma perspectiva analítica no debate sobre mudanças climáticas. In: KANASHIRO, Marta Mourão; DIAS, S. O.; VOGT, Carlos Alberto; PALLONE DE FIGUEIREDO, Simone. Comunicação, divulgação e percepção pública de ciência e tecnologia, ed. 1, De Petrus, 2013, p. 65.

DINIZ, Debora, CORRÊA, Marilena. Declaração de Helsinki: relativismo e vulnerabilidade, Cad. Saúde Pública, Rio de Janeiro, 17(3):679-688, mai-jun, 2001. Disponível online em: < http://unesdoc.unesco.org/images/0014/001461/146180por.pdf $>$ Acesso em 06-06-2018

DOCTORS' TRIAL AT NUREMBERG, International Physicians for the Prevention of Nuclear War and Physicians for Social Responsibility, Oct. 27, 1996. Disponível online em: http://www.law.yale.edu/outside/html/Publications/pub-katz.htm Acesso em 06-062018

DRAIN, Paul K. et al. Global Migration of Clinical Trials in the Era of Trial Registration. Nat Rev Drug Discov., 2014 March ; 13(3): 166-167.

EMA, Reflection paper on ethical and GCP aspects of clinical trials of medicinal products for human use conducted outside of the EU/EEA and submitted in marketing authorisation applications to the EU Regulatory Authorities, The European Medicines Agency Working Group on Clinical Trials conducted outside of the EU/EEA, EMA/121340/2011, 16 April 2012. Disponível online em:

http://www.ema.europa.eu/docs/en_GB/document_library/Regulatory_and_procedural_gui deline/2012/04/WC500125437.pdf Acesso em 06-06-2018

ENGELHARDT, H. Tristram, Bioethics after Four Decades: Looking to the Future, Portuguese Association of Bioethics, Oporto, Portugal, March 16, 2012.

ESTIGARA, Adriana. Consentimento livre e esclarecido na pesquisa envolvendo seres humanos. A distância entre o "dever ser" e o "ser". Revista Jus Navigandi, ISSN 15184862, Teresina, ano 11, n. 1144, 19 ago. 2006. Disponível online

em: <https://jus.com.br/artigos/8803> Acesso em 06-06-2018

EUROPEAN UNION - EU, REGULATION (EU) 2016/679 OF THE EUROPEAN PARLIAMENT AND OF THE COUNCIL of 27 April 2016 on the Protection of Natural Persons with Regard to the Processing of Personal Data and on the Free Movement of Such Data, and repealing Directive 95/46/EC (General Data Protection Regulation). Disponível online em: < http://eur-lex.europa.eu/legalcontent/en/TXT/?uri=CELEX\%3A32016R0679> Acesso em 06-06-2018

EUROPEAN UNION - EU, Regulation (EU) No 536/2014 of the European Parliament and of the Council of 16 April 2014 on Clinical Trials on Medicinal Products for Human Use, and repealing Directive 2001/20/EC. Disponível online em: < 
https://ec.europa.eu/health/sites/health/files/files/eudralex/vol1/reg_2014_536/reg_2014_536 en.pdf> Acesso em 06-06-2018

FADEN, R, BEAUCHAMP, T. A history and theory of informed consent, apud GRADY, Christine. The Changing Face of Informed Consent, The New England Journal of Medicine, 376;9, p. 856-859, March 2, 2017, p. 856.

FAUNCE, T. A., Will international human rights subsume medical ethics? Intersections in the UNESCO Universal Bioethics Declaration, Journal of Medical Ethics, 2004

FCM-UNICAMP, Glossário da Faculdade de Ciências Médicas da Unicamp, Centro de Pesquisas Clínicas (CPC). Disponível online em: https://www.fcm.unicamp.br/fcm/cpccentro-de-pesquisa-clinica/pesquisa-clinica/glossario Acesso em 06-06-2018

FIDLER, David P., International Law and Global Public Health, Kansas Law Review, Vol. 48, 1999. Disponível online em: $<$ http://www.repository.law.indiana.edu/facpub/652/> Acesso em 06-06-2018

FIDLER, David. Globalization of Public Health: Emerging Infectious Diseases and International Relations, Indiana Journal of Global Legal Studies: Vol. 5: Iss. 1, Article 2, 1997. Disponível online em: <h9p://www.repository.law.indiana.edu/ijgls/vol5/iss1/2> Acesso em 06-06-2018

FIDLER, David. Globalization, International Law, and Emerging Infectious Diseases. Emerging Infectious Diseases, Vol. 2, No. 2, April-June 1996.

FLORIANI, Dimas. Conhecimento, meio ambiente \& globalização. Curitiba: Juruá, 2004, $174 \mathrm{p}$

FREITAS, Márcia Araújo Sabino de. Capacidade, Transtorno Mental e Consentimento: as novas fronteiras do discurso médico-jurídico, Dissertação de Mestrado sob a orientação da Prof. Dra. Silmara Juny de Abreu Chinellato, Departamento de Direito Civil, Faculdade de Direito da Universidade de São Paulo, ano de obtenção 2012.

FRENCH, Howard. AIDS Research in Africa: Juggling Risks and Hopes, New York Times, Oct. 9, 1997. Disponível online em: < http://www.nytimes.com/1997/10/09/world/aids-research-in-africa-juggling-risks-andhopes.html> Acesso em 06-06-2018

GARRAFA, Volnei, PRADO, Mauro Machado. Mudanças na Declaração de Helsinki: fundamentalismo econômico, imperialismo ético e controle social. Cad Saúde Pública. 2001;17(6):1489-96.

GARRAFA, Volnei, SOLBAKK, JH, VIDAL, S, LORENZO, C. Between the needy and the greedy: the quest for a just and fair ethics of clinical research. J Med Ethics. 2010; 36(8):500-4.

GÉRARD, Philippe, L'esprit des droits. Philosophie des droits de l'homme, Bruxelles, St Louis, 2007, p. 158. 
GIDDENS, Anthony. Risk and Responsibility. Modern Law Review 62(1): 1-10, 1999.

GLOBAL FORUM FOR HEALTH RESEARCH, The 10/90 Report on Health Research 1999, Global Forum for Health Research, Geneva, Switzerland, 1999. Disponível online em: $<$ http://announcementsfiles.cohred.org/gfhr_pub/assoc/s14791e/s14791e.pdf $>$ Acesso em 06-06-2018

GONSALVES, Colin. Crookery of Clinical Trials, The Hindu, Health, 8 de abril de 2017. Disponível online em: $<$ http://www.thehindu.com/sci-tech/health/crookery-of-clinicaltrials/article17894601.ece> Acesso em 06-06-2018

GOODYEAR, Michael D. E., LEMMENS, Trudo, SPRUMONT, Dominique, TANGWA, Godfrey. Does the FDA have the authority to trump the Declaration of Helsinki?, $B M J ; 338$ :b1559, 2009. Disponível online em: <

http://www.bmj.com/content/338/bmj.b1559> Acesso em 06-06-2018

GRADY, Christine. Enduring and Emerging Challenges of Informed Consent. The New England Journal of Medicine, 372;9, p. 855-862, February 26, 2015.

GRADY, Christine. Payment of clinical research subjects, The Journal of Clinical Investigation, Volume 115, Number 7, pp. 1681-1687, 2005.

GRADY, Christine. The Changing Face of Informed Consent, The New England Journal of Medicine, 376;9, p. 856-859, March 2, 2017.

GRECO, Dirceu, WELSH, James. Direitos humanos, ética e prática médica, Rev. bioét. (Impr.) 24 (3): 443-51, 2016, p. 446. Disponível online em:

$<$ http://dx.doi.org/10.1590/1983-80422016243143 > Acesso em 06-06-2018

GUIMARÃES, M. C. S., NOVAES, S. C. Autonomia Reduzida e Vulnerabilidade:

Liberdade de Decisão, Diferença e Desigualdade. 2005, p. 3. Disponível online em: http://revistabioetica.cfm.org.br/index.php/revista bioetica/article/view/288 Acesso em 0606-2018

GUIVANT, Julia S. A teoria da sociedade de risco de Ulrich Beck: entre o diagnóstico e a profecia, Estudos Sociedade e Agricultura, 16 abril 2001: 95-112. Disponível em: http://bibliotecavirtual.clacso.org.ar/ar/libros/brasil/cpda/estudos/dezesseis/julia16.htm Acesso em 20-08-2017 Acesso em 06-06-2018

HANNIGAN, J. Sociologia ambiental. Petrópolis, RJ: Vozes, 2006. 270 p.

HARRIS, Gardiner. Concern Over Foreign Trials for Drugs Sold in U.S., New York Times, Research, June 21, 2010. Disponível online em:

$<$ http://www.nytimes.com/2010/06/22/health/research/22trial.html $>$ Acesso em 06-062018

HEARN, Kelly. The Rise of Unregulated Drug Trials in South America. The Nation, 21 de Setembro de 2011. Disponível online em: $<$ https://www.thenation.com/article/riseunregulated-drug-trials-south-america/> Acesso em 06-06-2018 
HENDERSON, L. J., Phisician and patient as a social system. New Engl. J. Med. 212: 819-823, 1935.

HOSSNE, Willian Saad; VIEIRA, Sônia. Experimentação com seres humanos. Ciência \& Ensino, Campinas, n. 2, 1997, p. 7-9. Disponível online em:

$<$ http://prc.ifsp.edu.br/ojs/index.php/cienciaeensino/article/viewFile/11/17> Acesso em 06-06-2018

ICMJ, Uniform Requirements for Manuscripts Submitted to Biomedical Journals, N Engl J Med 1997; 336:309-316, January 23, 1997. Disponível online em: <

http://www.nejm.org/doi/full/10.1056/NEJM199701233360422\#t=article $>$ Acesso em 0606-2018

ICMR, Ethical Guidelines for Biomedical Research on Human Participants, ICMR.NIC.IN, pg. 30. Disponível online em:

http://www.icmr.nic.in/ethical_guidelines.pdf. Acesso em 06-06-2018

INTERNATIONAL BIOETHICS COMMITTEE - IBC, Report of the IBC on the Possibility of Elaborating a Universal Instrument on Bioethics, SHS/EST/02/CIB-9/5 (Rev. 3) Paris, 13 June 2003. Disponível online em:

http://www.unesco.org/shs/ibc/en/igbc/s3/finrep_UIB en.pdf Acesso em 06-06-2018

JAYABARATHAN, Ajantha. Drug industry perverts proper medical practice, The Chronic Herald, April 29, 2017. Disponível online em:

$<$ http://thechronicleherald.ca/opinion/1463910-dr-aj-podcast-drug-industry-pervertsproper-medical-practice> Acesso em 06-06-2018

JONAS, Hans. Philosophical reflections on experimenting with human subjects. Daedalus, the Journal of the American Academy of Arts and Sciences 1969; 98: 219-247.

JUNGES, José Roque. Exigências éticas do consentimento informado. Revista Bioética 200715 (1): 77-82.

KALM, Leah M., SEMBA, Richard D. They Starved So That Others Be Better Fed: Remembering Ancel Keys and the Minnesota Experiment. JN The Journal of Nutrition, June 1, 2005, vol. 135 no. 6, 2005, p. 1347-1352. Disponível online em: < http://jn.nutrition.org/content/135/6/1347.long\#corresp-1> Acesso em 06-06-2018

KANT, Immanuel. Fundamentação da metafísica dos costumes. Lisboa: Edições 70, 1992.

KATZ, Jay. Experimentation with Human Beings: The Authority of the Investigator,

Subject, Professions, and State in the Human Experimentation Process. New York: Russell Sage Foundation, 1972.

KATZ, Jay. Human Experimentation and Human Rights, 38 ST. Louis U. L.J. 7, 17 (1993).

KATZ, Jay. Human Sacrifice and Human Experimentation: Reflections at Nuremberg, Address at the Conference Commemorating the Fiftieth Anniversary of the Nazi Doctors' Trial at Nuremberg Convened by International Physicians for the Prevention of Nuclear War and Physicians for Social Responsibility (Oct. 27, 1996), p. 408. Disponível online 
em: http://www.law.yale.edu/outsidelhtrnl/Publications/pub-katz.htrn Acesso em 06-062018

KEEN, Judy. Push grows for 'right to try' laws that loosen access to experimental treatments, Star Tribune, 5 de Julho de 2017. Disponível online em:

$<$ http://www.startribune.com/push-grows-for-right-to-try-laws-that-loosen-access-toexperimental-treatments/432552223/> Acesso em 06-06-2018

KERR-CORRÊA, Florence; GUTIERREZ, Pilar Lecussán. Ética, pesquisa e ensino em Psiquiatria, p. 37-52, 2007

KHAN, Fazal. The human factor: Globalizing ethical standards in drug trials through market exclusion, 57 DePaul L. Rev. 877, Summer, 2008.

KIRSHNER, Jodie A. A Call for the EU to Assume Jurisdiction over Extraterritorial Corporate Human Rights Abuses. Northwestern University Journal of International Human Rights, 13 Nw. U. J. Int'l Hum. Rts. 1, 2015.

KOTTOW, Miguel. De Helsinki a Fortaleza: una Declaración desangrada. Rev. Bioét., Brasília, v. 22, n. 1, p. 28-33, Apr. 2014. Disponível online em: $<$ http://www.scielo.br/scielo.php?script $=$ sci arttext\&pid $=\mathrm{S} 1983-$ $80422014000100004 \& \operatorname{lng}=\mathrm{en} \& n r m=$ iso $>$ Acesso em 06-06-2018

LACEY, Hugh. Existe uma distinção relevante entre valores cognitivos e sociais?, Scientiae Studia, vol. 01, n. 02, p. 121-40, 2003.

LACEY, Hugh. Impartiality, Neutrality and Autonomy: Three components of the idea that science is value free. Presented at the conference, "Value Free Science: Illusion or Ideal?", Center for Ethics and Values in the Sciences, University of Alabama at Birmingham, February 23-25, 2001.

LACEY, Hugh. Is Science Value Free? values and scientific understanding. London: Routledge, 1999.

LAFER, Celso, Declaração Universal dos Direitos Humanos (1948) in História da Paz: os tratados que desenharam o planeta, de organização, Demétrio Magnoli, São Paulo: Contexto, 2008, p. 297-329.

LAFRANIERE, Sharon et al., The Dilemma: Submit or Suffer 'Uninformed Consent' Is Rising Ethic of the Drug Test Boom, Washington Post, The Body Hunters, Dec. 19, 2000. Disponível online em: $<$ http://www.washingtonpost.com/wpdyn/content/article/2008/10/01/AR2008100101150.html > Acesso em 06-06-2018

LAMAS, E, FERRER, M, MOLINA, A, SALINAS, R, et al. A comparative analysis of biomedical research ethics regulation systems in Europe and Latin America with regard to the protection of human subjects. Journal of Medical Ethics, J Med Ethics;36: 750 e 753, 2010

LANE, Síle. The hidden side of clinical trials, TED Talks, Sep 28, 2016. 
LAVERY, James V. Putting International Research Ethics Guidelines To Work for the Benefit of Developing Countries. Volume 4, Issue 2, Article 4, Yale Journal of Health Policy, Law, and Ethics, 2004. Disponível online em:

http://digitalcommons.law.yale.edu/yjhple/vol4/iss2/4 Acesso em 06-06-2018

LECHOPIER, Nicolas, Sciences, valeurs et pluralisme chez Hugh Lacey, in Pierron, J-P; Parizeau, M-H (dir.), Nature, technologie, éthique. Dialogue Europe, Asie, Amériques.

Québec, Les Presses de l'Université Laval, 2012

LECHOPIER, Nicolas. Ética e justiça nas pesquisas sediadas em comunidades: o caso de uma pesquisa ecossistêmica na Amazônia. Sci. stud. [online]. 2011, vol.9, n.1 [cited 201605-26], pp.129-147. Disponível online em:

$<$ http://www.scielo.br/scielo.php?script $=$ sci_arttext\&pid $=\mathrm{S} 1678$ -

$31662011000100007 \& \operatorname{lng}=$ en\&nrm $=$ iso $>$. ISSN 1678-

3166. http://dx.doi.org/10.1590/S1678-31662011000100007 Acesso em 06-06-2018

LEMMENS, T., ELLIOTT, C. Justice for the professional guinea pig. The American Journal of Bioethics, Spring 2001, Volume 1, Number 2, p. 51-52.

LEMMENS, Trudo. Pharmaceutical Knowledge Governance: A Human Rights

Perspective, Journal of Law, Medicine and Ethics, Vol. 41, Issue 1 (Spring 2013), pp. 163184

LOBATO, L.; CAÇADOR, B.; GAZZINELLI, M. Legibilidade dos termos de consentimento livre e esclarecido em ensaios clínicos. Revista Bioética, Brasília, v. 21, n. 3, p. 560, dez. 2013, p. 562. Disponível online em: $<$ http://revistabioetica.cfm.org.br/index.php/revista_bioetica/article/view/777/939> Acesso em 06-062018

LOYD-ROBERTS, Sue. Have India's poor become human guinea pigs?, BBC, Newsnight, Magazine, 1 de Novembro de 2012. Disponível online em:

$<$ http://www.bbc.com/news/magazine-20136654> Acesso em 06-06-2018

LURIE, P., WOLFE, S. Unethical trials of interventions to reduce perinatal transmission of the human immunodeficiency virus in developing countries. New England Journal of Medicine, 337:853-856, 1997.

MARICONDA, Pablo \& LACEY, Hugh. A águia e os estorninhos. Galileu e a autonomia da ciência. Tempo Social; Rev. Sociol. USP, S. Paulo, 13(1): 49-65, maio de 2001.

MARICONDA, Pablo Rúben, Galileu e a Ciência Moderna. Revista Especiaria, Santa Cruz, n. 16, p. 267-292. Disponível online em :

http://www.uesc.br/revistas/especiarias/ed16/16_2_galileu_e_a_ciencia_moderna.pdf

Acesso em 06-06-2018

MCCANCE, R. A., The practice of experimental medicine. Proc. Roy. Soc. Med. 44:189194, 1951.

MCGOEY, Lindsey. No Such Thing as a Free Lunch: The Gates Foundation and the price of philanthropy. Verso Books, 2015, 304 p. 
MEIER, Benjamin Mason, International Criminal Prosecution of Physicians: A Critique of Professors Annas and Grodin's Proposed International Medical Tribunal. Boston University School of Law, American Journal of Law \& Medicine, 30 Am. J. L. and Med. 419, 2004.

MEIER, Benjamin Mason, International Protection of Persons Undergoing Medical Experimentation: Protecting the Right of Informed Consent, 20 Berkeley J. Int'1 L. 513, 532-33 (2002).

MEMORIAL DO HOLOCAUSTO (EUA). As Experiências Médicas Nazistas. Enciclopédia do Holocausto. Disponível online em: $<$ https://www.ushmm.org/wlc/ptbr/article.php?ModuleId=10005168 $>$ Acesso em 06-062018

MISETA, Ed. Google and Apple Compete for Clinical Trial Supremacy, Clinical Leader, May 3, 2017. Disponível online em: $<$ https://www.clinicalleader.com/doc/google-andapple-compete-for-clinical-trial-supremacy-0001> Acesso em 06-06-2018

MITCHAM, C. (Ed.). Encyclopedia of science, technology, and ethics, Vols. 1, Farmington Hills, MI: Thomson/Gale, 2005.

MITCHAM, C. (Ed.). Encyclopedia of science, technology, and ethics, Vols. 2, Farmington Hills, MI: Thomson/Gale, 2005.

MUÑOZ, D., MUÑOZ, D.R. O ensino da ética nas faculdades de medicina do Brasil. Rev. Brasileira de Educação Médica 2003; 27(2): 114-24.

NAPPO, Solange A., IAFRATE, Giovanna B., SANCHEZ, Zila M., Motives for participating in a clinical research trial: a pilot study in Brazil, BMC Public Health 2013, 13:19. Disponível online em: < http://www.biomedcentral.com/1471-2458/13/19> Acesso em 06-06-2018

NASSER, Salem Hikmat. Desenvolvimento, costume internacional e soft law. In: AMARAL JÚNIOR, Alberto do (org.). Direito Internacional e desenvolvimento. $1^{\mathrm{a}}$. Ed. Barueri: Manole, 2005.

NATIONAL BIOETHICS ADVISORY COMMISSION - NBAC. Nat'l Bioethics Advisory Comm'n, Ethical And Policy Issues In International Research: Clinical Trials In Developing Countries, Volume 1: Report And Recommendations of the National Bioethics Advisory Commission 37, 2001.

NEYRET, Laurent. La transformation du crime contre l'humanité in Le crime contre l'humanité, M. Delmas-Marty et alia, PUF, 2009.

NITIN, B. There's a new tool to drag poor men into India's murky drug trials, WhatsApp: TNM Investigation, The News Minute, June 06, 2017. Disponível online em:

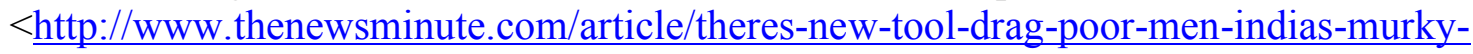
drug-trials-whatsapp-tnm-investigation-63210> Acesso em 06-06-2018 
NÚCLEO DE APOIO À PESQUISA CLÍNICA -NAPesq (Hospital das Clínicas da Faculdade de Medicina da Universidade de São Paulo - HCFMUSP), Glossário.

Disponível online em: http://napesq.hc.fm.usp.br/glossario.php Acesso em 06-06-2018

NUFFIELD COUNCIL ON BIOETHICS. The Ethics of Research Related to Healthcare in Developing Countries. London: Nuffield Council, 2002; p. 87.

NUREMBERG MILITARY TRIBUNALS, Trials of war criminal before the Nuremberg Military Tribunals. Control Council Law, 1949;10(2):181-182. Disponível online em: https://www.loc.gov/rr/frd/Military_Law/pdf/NT_war-criminals_Vol-XIII.pdf Acesso em 06-06-2018

NUREMBERG MILITARY TRIBUNALS, Trials of war criminal before the Nuremberg Military Tribunals. Control Council Law 10, vols. 1 and 2 (Washington, D.C.: Superintendent of Documents, U.S. Government Printing Office, 1951).

PARLIAMENT OF INDIA, Report on the functioning of the central drugs standard control organization (CDSCO), Parliamentary Standing Committee on Health and Family Welfare, 8 MAY, 2012. Disponível online em:

http://164.100.47.5/newcommittee/reports/englishcommittees/committee $\% 20$ on $\% 20$ health $\% 20$ and $\% 20$ family $\% 20$ welfare/59.pdf Acesso em 06-06-2018

PERRONE-MOISÉS, Cláudia. Antecedentes históricos do estabelecimento do Tribunal Penal Internacional. Revista da Faculdade de Direito, Universidade de São Paulo, v. 98, p. 573-579, 2003.

PETRYNA, Adriana. Experimentality: on the global mobility and regulation of human subjects research. Polar: Political and Legal Anthropology Review, Vol 30, Number 2, pp. 288-304, 2007.

PETRYNA, Adriana. When Experiments Travel: Clinical Trials and the Global Search for Human Subjects, Princeton, Princeton University Press, 2009.

PHYSICS WORLD, Nobel Prize winner calls for ethics oath, News, Dec 19, 1997. Disponível online em: $<$ http://physicsworld.com/cws/article/news/1997/dec/19/nobelprize-winner-calls-for-ethics-oath $>$ Acesso em 06-06-2018

PLOMER, Aurora. The Law and Ethics of Medical Research: International Bioethics and Human Rights, New York, Ed. Routledge-Cavendish, 2005.

PONTES, Felipe. Terceirizando cobaias: Farmacêuticas de países ricos usam cada vez mais nações pobres para testar seus remédios - e são acusadas de experimentos antiéticos, Revista Galileu, Reportagem. Disponível online em: < http://revistagalileu.globo.com/Revista/Common/0,EMI269853-17773,00TERCEIRIZANDO+COBAIAS.html> Acesso em 06-06-2018

POTTER, Van Rensselaer. Bioethics: the science of survival, Perspectives in Biology and Medicine, 14: 127-173, 1970. Disponível online em: http://pages.uoregon.edu/nmorar/Nicolae_Morar/Phil335Fall15 files/Potter_BioethicsThe ScienceofSurvival.pdf Acesso em 06-06-2018 
PRESTON, Juliet. An "OpenTable" approach to clinical trial recruitment, Med City News, Jun 23, 2017. Disponível online em: $<$ http://medcitynews.com/2017/06/opentableapproach-clinical-trial-recruitment/> Acesso em 06-06-2018

RAI, Saritha. Drug Companies Cut Costs With Foreign Clinical Trials, New York Times, International Business, 24 de Fevereiro de 2005. Disponível online em:

$<$ http://www.nytimes.com/2005/02/24/business/drug-companies-cut-costs-with-foreignclinical-trials.html $>$ Acesso em 06-06-2018

RICOEUR, P. Les trois niveaux du jugement médical. Esprit, Paris, décembre, 1996

RIVA, Gabriela R. Saab. Água, um Direito Humano. São Paulo, Paulinas, 2016.

ROBINSON, W. M., UNRUH, B.T. The Hepatitis Experiments in the Willowbrook State School. Emanuel EJ, Grady C, Lie RF, et al, editors: The Oxford Textbook of Clinical Research Ethics. New York, Oxford University Press, In Press. p. 80-5. Disponível online em:

http://science.jburroughs.org/mbahe/BioEthics/Articles/WilliowbrookRobinson2008.pdf Acesso em 06-06-2018

ROCHA, Jan. Mengele letters reveal life ended in pain and poverty, The Guardian, World News, 23 November 2004. Disponível online em:

$<$ https://www.theguardian.com/world/2004/nov/23/secondworldwar $>$ Acesso em 06-062018

ROUSSEAU, Jean-Jacques. Discurso sobre as ciências e as artes. Tradução por Nélson Jahr Garcia. Ridendo Castigat Moraes, Edição eletrônica.

SCHAEFER, F., Bioética, Biodireito e Direitos Humanos, in: MEIRELLES, Jussara Maria Leal de (coord.). Biodireito em discussão. Curitiba: Juruá, 2008.

SCHMIDT, H., MEHRING, S., MCMILLAN, J., Interpreting the Declaration of Helsinki (2008): "Must", "Should" and Different Kinds of Obligation, Medicine and Law, Bioethics, 29, p. 565-591, 2010.

SCHRAMM, Fermin R., Ética ambiental e bioética global, Revista Redbioética/UNESCO, Año 5, 1 (9): 71-78, enero - junio 2014, p. 75.

SEGRE, Marco. Reflections on bioethics: consolidation of the principle of autonomy and legal aspects. Cad. Saúde Pública, Rio de Janeiro, v. 15, supl. 1, p. S91-S98, 1999. Disponível online em: $<$ http://www.scielo.br/scielo.php?script=sci arttext\&pid=S0102311X1999000500010\&lng=en\&nrm=iso $>$ Acesso em 06-06-2018

SHAH, J.Y., PHADTARE, A, RAJGOR, D, VAGHASIA, M, PRADHAN, S, ZELKO, H, PIETROBON, R. What leads Indians to participate in clinical trials? A meta-analysis of qualitative studies. Plos One, v. 5, p. e10730, 2010.

SHAMOO, Adil E., KATZEL, Leslie I. Urgent Ethical Challenges in Human Subjects Protection, Journal of Clinical Research Best Practice, Vol. 3, No. 3, March 2007. 
SHAPIRO, Harold T., MESLIN, Eric M. Ethical Issues In The Design And Conduct Of Clinical Trials In Developing Countries. The New England Journal of Medicine, Vol. 345, No. 2, July 12, 2001.

SHAW, Malcolm N. International Law, Cambridge, University Press, Fifth Edition, 2003.

SIDDIQUI, Zeba. Serial testers and cursory checks: India's flawed generic drug trials business, Reuters, 28 de Dezembro de 2016. Disponível online em:

$<$ http://www.reuters.com/article/us-india-drug-testing-insight-idUSKBN14G1U6 $>$ Acesso em 06-06-2018

SLOAT, Bill, EPSTEIN, Keith. Living Proof: In U.S-run study, Ugandans expected treatment. They got dummy pills, The Plain Dealer, Monday, November 9, 1998.

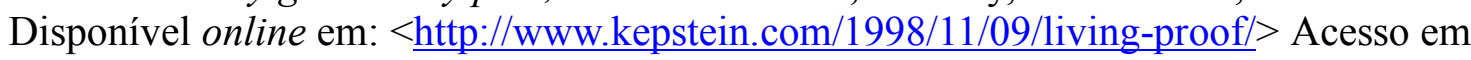
06-06-2018

SLOMKA, J. et al., Perceptions of Financial Payment for Research Participation among African-American Drug Users in HIV Studies. J Gen Intern Med 22(10):1403-9.

SLOVIC, Paul. The Psychology of Risk, Psychology Colloquia, Paper 9, 2012. Disponível online em: http://fordham.bepress.com/psych_colloquia/9 Acesso em 06-06-2018

SPIELMAN, Bethany. Offshoring experiments, outsourcing public health Corporate Accountability and State Responsibility for Violating the International Prohibition on Nonconsensual Human Experimentation, The Globalization of Health Care, Oxford University Press, p. 286-301, 2013.

SRINIVASAN, Sandhya. Trials and tribulations: Ethics of clinical trials and vaccine research in India, Himal (Southasian), 17 de Janeiro de 2017. <Disponível online em: $<$ http://himalmag.com/ethics-of-clinical-trials-india/> Acesso em 06-06-2018

STANFORD UNIVERSITY, Guide to Conducting Clinical Trials in India, January 2017. Disponível online em: https://researchcompliance.stanford.edu/hs/research/documents/Stanford\%20\%20Guide $\% 20$ to $\% 20$ Conducting\%20Research $\% 20$ in $\% 20$ India $\% 201.17 \% 20$ pdf[3].pdf Acesso em 06-06-2018

THE GUARDIAN, Thalidomide scandal: 60-year timeline, The Guardian, Health, 1 September 2012. Disponível online em:

$<$ https://www.theguardian.com/society/2012/sep/01/thalidomide-scandal-timeline $>$ Acesso em 06-06-2018

THE WHITE HOUSE, Remarks by the President in Apology for Study Done in Tuskegee, Office of the Press Secretary, May 16, 1997. Disponível online em: https://www.cdc.gov/tuskegee/clintonp.htm Acesso em 06-06-2018

TNN, Include local advice for drug trials in India, Times of India, 9 de Jul de 2017. Disponível online em: < http://timesofindia.indiatimes.com/city/kolkata/include-localadvice-for-drug-trials-in-india/articleshow/59509747.cms $>$ Acesso em 06-06-2018 
TOMANIK, José Pompeu, Juramento de Hipócrates, Revista da Associação Paulista de Medicina, Janeiro 2009 - No 198, p. 1-4.

TRIBUNAL PENAL INTERNACIONAL, Estatuto de Roma (Documento A/CONF.183/9, de 17 julho de 1998). Disponível online em: https://www.icc-cpi.int/nr/rdonlyres/ea9aeff75752-4f84-be94-0a655eb30e16/0/rome_statute_english.pdf Acesso em 06-06-2018

TRINDADE, E.S., AZAMBUJA, L., ANDRADE, J.P., GARRAFA, V. O médico frente ao diagnóstico e prognóstico de câncer avançado, Revista da Associação Médica Brasileira, 2007; 53(1): 68-74.

U.S. CENTERS FOR DISEASE CONTROL AND PREVENTION, Addressing emerging infectious disease threats: a prevention strategy for the united states (Executive Summary), MMWR 1994; 43 (No. RR-5), 1994.

U.S. DEPARTMENT OF HEALTH AND HUMAN SERVICES - HHS, Code of Federal Regulations, 2014, Title 45, Part 46. Disponível online em: $<$ http://www.hhs.gov/ohrp/regulations-and-policy/regulations/45-cfr-46/> Acesso em 0606-2018

U.S. DEPARTMENT OF HEALTH AND HUMAN SERVICES - HHS, Federal Policy for the Protection of Human Subjects, Rules and Regulations Federal Register, Vol. 82, No. 12, Thursday, January 19, 2017. Disponível online em: https:/Www.gpo.gov/fdsys/pkg/FR2017-01-19/pdf/2017-01058.pdf Acesso em 06-06-2018

U.S. FOOD AND DRUG ADMINISTRATION (FDA), Code of Federal Regulations, Title 21, Volume 1, (Revised as of April 1, 2017), Sec. 50.25. Elements of informed consent. Disponível online em:

$<$ https://www.accessdata.fda.gov/scripts/cdrh/cfdocs/cfcfr/CFRSearch.cfm?fr=50.25>

Acesso em 06-06-2018

U.S. FOOD AND DRUG ADMINISTRATION (FDA). Human subject protection; foreign clinical studies not conducted under an investigational new drug application. 21 CFR part 312. Final rule 28 April 2008, effective, October 27 2008. Disponível online em:

$<$ www.regulations.gov/fdmspublic/component/main?main $=$ DocumentDetail\&o $=09000064$ 80537f08. $>$ Acesso em 06-06-2018

U.S. SUPREME COURT, United States v. Stanley, 483 U.S. 669, 687 (1987). Disponível

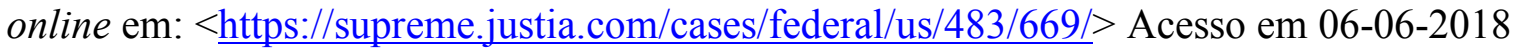

UN GENERAL ASSEMBLY, International Covenant on Civil and Political Rights, 16 December 1966, United Nations, Treaty Series, vol. 999, p. 171. Disponível online em: https://treaties.un.org/doc/publication/unts/volume\%20999/volume-999-i-14668english.pdf Acesso em 06-06-2018

UNESCO, Declaração Universal sobre Bioética e Direitos Humanos, (33 C/Resolution 15, 19 October 2005).

UNICAMP, Quais são as fases da pesquisa clínica?, Faculdade de Ciências Médicas, 
Centro de Pesquisa Clínica - CPC, Campinas. Disponível online em: <

http://www.fcm.unicamp.br/fcm/cpc-centro-de-pesquisa-clinica/pesquisa-clinica/quais-saofases-da-pesquisa-clinica $>$ Acesso em 06-06-2018

UNITED STATES DEPARTMENT OF HEALTH AND HUMAN SERVICES - HHS, Belmont Report: Ethical Principles and Guidelines for the Protection of Human Subjects of Research, Report of the National Commission for the Protection of Human Subjects of Biomedical and Behavioural Research (OPRR Reports - NIH - PHS - HHS, April 18, 1979).

VEATCH, R. M., Models for ethical medicine in a revolutionary age. The Hastings Center Report, Vol. 2, No. 3 (Jun., 1972), pp. 5-7.

WENDLER, David. What Should Be Disclosed to Research Participants?, Am J Bioeth. 2013, 13(12):3-8. Disponível online em:

$<$ https://www.ncbi.nlm.nih.gov/pubmed/24256522> Acesso em 06-06-2018

WHO Framework Convention on Tobacco Control. Geneva: World Health Organization; 2003. Disponível online em: < $\underline{\mathrm{http}} / / / \mathrm{www}$.who.int/fctc/text_download/en/> Acesso em 0606-2018

WHO, Guidelines for good clinical practice (GCP) for trials on pharmaceutical products, Technical Report Series, No. 850, 1995. Disponível online em:

$<$ http://apps.who.int/medicinedocs/pdf/whozip13e/whozip13e.pdf $>$ Acesso em 06-06-2018

WHO, International ethical guidelines for biomedical research involving human subjects. Geneva: Council for International Organizations of Medical Sciences, 1993. Disponível online em: < http://www.who.int/ethics/research/en/> Acesso em 06-06-2018

WHO, Operational Guidelines for Ethics Committees That Review Biomedical Research (TDR/PRD/ETHICS/2000.1), Geneva, 2000. Disponível online em:

$<$ http://www.who.int/tdr/publications/documents/ethics.pdf?ua=1 $>$ Acesso em 06-06-2018

WMA, Declaração de Helsinque da Associação Médica Mundial, Princípios Éticos para Pesquisa Médica Envolvendo Seres Humanos, Emendada pela 64ª Assembleia Geral da WMA, Fortaleza, Brasil, Outubro 2013.

WMA, Declaration of Helsinki, Ethical Principles for Medical Research Involving Human Subjects, 64th WMA General Assembly, Fortaleza, Brazil, October 2013. Disponível online em: $<$ https://www.wma.net/policies-post/wma-declaration-of-helsinki-ethicalprinciples-for-medical-research-involving-human-subjects/> Acesso em 06-06-2018

WORLD BANK, World Development Report 1993 Investing in Health, New York, Oxford University Press. Disponível online:

$<$ https://openknowledge.worldbank.org/bitstream/handle/10986/5976/9780195208900_fm. pdf> Acesso em 06-06-2018

WORLD HEALTH ASSEMBLY. International health regulations (2005). Geneva: World Health Organization, 2006. Disponível online em:

$<\underline{\text { http://apps.who.int/iris/bitstream/10665/246107/1/9789241580496-eng.pdf?ua }=1>}$ 
Acesso em 06-06-2018

WORLD HEALTH ORGANIZATION - WHO, Bulletin of the World Health Organization Volume 86, Number 8, August 2008, 577-656. Disponível online em:

$<$ http://www.who.int/bulletin/volumes/86/8/08-051110/en/> Acesso em 06-06-2018

WORLD HEALTH ORGANIZATION - WHO, Guidelines for contributors, Bull World Health Organ 2009; 87: p. 79-80. Disponível online em: http://www.who.int/bulletin/contributors/current Ruidelines.pdf. Acesso em 06-06-2018

WORLD HEALTH ORGANIZATION - WHO, Investing in Health Research and Development: Report of the Ad Hoc Committee on Health Research Relating to Future Intervention Options, WHO, Geneva, Switzerland, 1996. Disponível online em: $<$ http://apps.who.int/iris/bitstream/10665/63024/1/TDR_Gen_96.1_pp1-34.pdf $>$ Acesso em 06-06-2018

WORLD HEALTH ORGANIZATION - WHO, Investing in Health Research and Development: Report of the Ad Hoc Committee on Health Research Relating to Future Intervention Options, WHO, Geneva, Switzerland, 1996. Disponível online em: < http://apps.who.int/iris/bitstream/10665/63024/1/TDR_Gen_96.1_pp1-34.pdf > Acesso em 06-06-2018

WORLD HEALTH ORGANIZATION - WHO, The 10/90 report on health research, 1999. Geneva: Global Forum for Health Research; 1999; World Health Organization WHO, Bulletin of the World Health Organization Volume 86, Number 8, August 2008, 577-656. Disponível online em: $<$ http://www.who.int/bulletin/volumes/86/8/08-

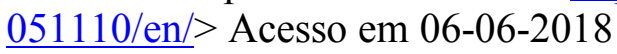

WORLD HEALTH ORGANIZATION - WHO, The 10/90 report on health research, 1999. Geneva: Global Forum for Health Research; 1999.

ZUBEN, Newton Aquiles Von. As investigações cientificas e a experimentação humana: aspectos bioéticos. Revista Bioéthikos, Centro Universitário São Camilo, 2007;1(1):12-23, p. 13.

ZUBEN, Newton Aquiles Von. Bioética e Biosegurança. As tecnociências e a transcendência de limites. Gestión y Ambiente, v. 10, p. 115-124, 2007.

ZUBEN, Newton Aquiles Von. O pensar: Hannah Arendt e Paul Ricoeur. Pro-Posições (Unicamp), Campinas, v. 16, p. 22-37, 1999.

ZUBEN, Newton Aquiles Von. Vulnerabilidade e finitude: a ética do cuidado do outro. Belo Horizonte, Síntese, Rev. de Filosofia, V. 39, N. 125, 433-456, 2012. 


\section{ANEXO I \\ CÓDIGO DE NUREMBERG DE 1947 \\ Trials of war criminal before the Nuremberg Military Tribunals. \\ Control Council Law 1949;10(2):181-182.}

1. O consentimento voluntário do ser humano é absolutamente essencial. Isso significa que as pessoas que serão submetidas ao experimento devem ser legalmente capazes de dar consentimento; essas pessoas devem exercer o livre direito de escolha sem qualquer intervenção de elementos de força, fraude, mentira, coação, astúcia ou outra forma de restrição posterior; devem ter conhecimento suficiente do assunto em estudo para tomarem uma decisão. Esse último aspecto exige que sejam explicados às pessoas a natureza, a duração e o propósito do experimento; os métodos segundo os quais será conduzido; as inconveniências e os riscos esperados; os efeitos sobre a saúde ou sobre a pessoa do participante, que eventualmente possam ocorrer, devido à sua participação no experimento. $\mathrm{O}$ dever e a responsabilidade de garantir a qualidade do consentimento repousam sobre o pesquisador que inicia ou dirige um experimento ou se compromete nele. São deveres e responsabilidades pessoais que não podem ser delegados a outrem impunemente.

2. O experimento deve ser tal que produza resultados vantajosos para a sociedade, que não possam ser buscados por outros métodos de estudo, mas não podem ser feitos de maneira casuística ou desnecessariamente.

3. O experimento deve ser baseado em resultados de experimentação em animais e no conhecimento da evolução da doença ou outros problemas em estudo; dessa maneira, os resultados já conhecidos justificam a condição do experimento.

4. O experimento deve ser conduzido de maneira a evitar todo sofrimento e danos desnecessários, quer físicos, quer materiais.

5. Não deve ser conduzido qualquer experimento quando existirem razões para acreditar que pode ocorrer morte ou invalidez permanente; exceto, talvez, quando o próprio médico pesquisador se submeter ao experimento.

6. O grau de risco aceitável deve ser limitado pela importância do problema que o pesquisador se propõe a resolver.

7. Devem ser tomados cuidados especiais para proteger o participante do experimento de qualquer possibilidade de dano, invalidez ou morte, mesmo que remota.

8. O experimento deve ser conduzido apenas por pessoas cientificamente qualificadas.

9. O participante do experimento deve ter a liberdade de se retirar no decorrer do experimento.

10. O pesquisador deve estar preparado para suspender os procedimentos experimentais em qualquer estágio, se ele tiver motivos razoáveis para acreditar que a continuação do experimento provavelmente causará dano, invalidez ou morte para os participantes 


\section{ANEXO II \\ JURAMENTO HIPOCRÁTICO (Séc. 450 a.C.)}

Juro por Apolo, médico, e por Esculápio, por Hygéia, por Panacéia, e por todos os deuses e deusas, constituindo-os juízes de como, na medida das minhas forças e do meu juízo, haverei de fazer executado o seguinte juramento e o seguinte compromisso:

- considerarei aquele que me ensinou esta arte o igual a meus pais; prometerei partilhar com ele os meus bens;

- e, se padecer necessidades, torná-lo-ei participante deles; considerarei os seus filhos meus irmãos, e, se quiserem aprender esta arte, haverei lh'a ensinar sem qualquer salário nem compromisso.

- Dos preceitos, das lições ouvidas e de todas as mais instruções farei a transmissão aos meus filhos, aos filhos do meu mestre, aos discípulos ligados por uma obrigação, tendo jurado segundo a lei médica; porém, a ninguém mais.

- Aplicarei os regimes de vida para a utilidade dos doentes de acordo com a minha capacidade e o meu juízo, abstendo-me de qualquer malefício ou dano (injustiça).

- Não porei nenhum veneno em mãos de ninguém, mesmo que me peçam, nem tomarei a iniciativa de o aconselhar; igualmente não entregarei a nenhuma mulher um pessário abortivo. Passarei a minha vida e praticarei a minha arte pura e santamente.

- Não operarei de nenhum modo os padecentes de litíase (não praticarei a litotomia), deixando a prática desse ato aos profissionais.

- Em quantas casas entrar, fá-lo-ei só para a utilidade dos doentes, abstendo-me de todo o mal voluntário e de toda voluntária maleficência e de qualquer outra ação corruptora, tanto em relação a mulheres quanto a jovens, sejam livres ou escravos.

- O que for que veja ou ouça, concernente à vida das pessoas, no exercício da minha profissão ou fora dela, e que não haja necessidade de ser revelado, eu calarei, julgando que tais coisas não devem ser divulgadas.

- Se eu cumprir fielmente este juramento sem infringir, seja-me dado gozar, feliz, da minha profissão, honrado por todos os homens, em todos os tempos; mas se o violar e perpetrar um perjúrio, que o contrário me suceda. 


\section{ANEXO III \\ JURAMENTO HIPOCRÁTICO ou Declaração de Genebra \\ (reformulado pela Assembleia Geral da Associação Médica Mundial, Suíça, 1948)}

Ao ser admitido como membro da profissão médica:

Comprometo-me solenemente a consagrar a minha vida ao serviço da humanidade. Dedicarei aos meus mestres o respeito e a gratidão a que fazem jus. Exercerei minha profissão com consciência e dignidade. A saúde do meu paciente constituirá minha principal preocupação. Respeitarei os segredos que me forem confiados. Manterei, por todos os meios ao meu alcance, a honra e as nobres tradições da profissão médica. Meus colegas serão meus irmãos. Não permitirei que questões de religião, nacionalidade, "raça", política partidária ou situação social se interponham entre o meu dever e meu paciente. Conservarei o máximo respeito pela vida humana, desde sua concepção. Mesmo sob ameaça, não utilizarei meus conhecimentos médicos contra as leis da humanidade. Assumo esses compromissos, solenemente, livremente e por minha honra. 


\begin{abstract}
ANEXO IV
JURAMENTO HIPOCRÁTICO ou Declaração de Genebra

(reformulada pela Assembleia Geral da Associação Médica Mundial, Chicago, 2017)
\end{abstract}

COMO MEMBRO DA PROFISSÃO MÉDICA:

- PROMETO SOLENEMENTE consagrar a minha vida ao serviço da humanidade;

- A SAÚDE E O BEM-ESTAR DO MEU DOENTE serão as minhas primeiras preocupações; - RESPEITAREI a autonomia e a dignidade do meu doente;

- GUARDAREI o máximo respeito pela vida humana;

- NÃO PERMITIREI que considerações sobre idade, doença ou deficiência, crença religiosa, origem étnica, sexo, nacionalidade, filiação política, raça, orientação sexual, estatuto social ou qualquer outro fator se interponham entre o meu dever e o meu doente; - RESPEITAREI os segredos que me forem confiados, mesmo após a morte do doente;

- EXERCEREI a minha profissão com consciência e dignidade e de acordo com as boas práticas médicas;

- FOMENTAREI a honra e as nobres tradições da profisssão médica;

- GUARDAREI respeito e gratidão aos meus mestres, colegas e alunos pelo que lhes é devido;

- PARTILHAREI os meus conhecimentos médicos em benefício dos doentes e da melhoria dos cuidados de saúde;

- CUIDAREI da minha saúde, bem-estar e capacidades para prestar cuidados da maior qualidade;

- NÃO USAREI os meus conhecimentos médicos para violar direitos humanos e liberdades civis, mesmo sob ameaça; FAÇO ESTAS PROMESSAS solenemente, livremente e sob palavra de honra; 


\begin{abstract}
ANEXO V
Crescimento anual do número de testes clínicos no âmbito global e na Índia.
\end{abstract}

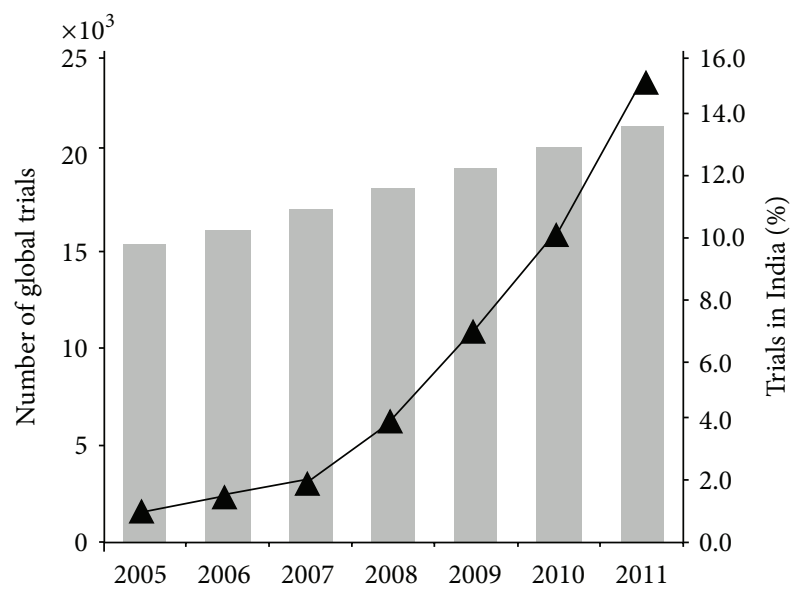

FIGURE 1: Number of global trials and the proportion in India. Source: The Boston Consulting Group and Business Communications Company data quoted in Mishra [21]. 


\section{ANEXO VI \\ Elementos para o Consentimento Informado da Regulação Federal Norteamericana}

[Code of Federal Regulations]

[Title 21, Volume 1]

[Revised as of April 1, 2017]

[CITE: 21CFR50.25]

\section{TITLE 21--FOOD AND DRUGS \\ CHAPTER I--FOOD AND DRUG ADMINISTRATION \\ DEPARTMENT OF HEALTH AND HUMAN SERVICES \\ SUBCHAPTER A--GENERAL}

PART 50 -- PROTECTION OF HUMAN SUBJECTS

Subpart B--Informed Consent of Human Subjects

Sec. 50.25 Elements of informed consent.

(a) Basic elements of informed consent. In seeking informed consent, the following information shall be provided to each subject:

(1) A statement that the study involves research, an explanation of the purposes of the research and the expected duration of the subject's participation, a description of the procedures to be followed, and identification of any procedures which are experimental.

(2) A description of any reasonably foreseeable risks or discomforts to the subject.

(3) A description of any benefits to the subject or to others which may reasonably be expected from the research.

(4) A disclosure of appropriate alternative procedures or courses of treatment, if any, that might be advantageous to the subject.

(5) A statement describing the extent, if any, to which confidentiality of records identifying the subject will be maintained and that notes the possibility that the Food and Drug Administration may inspect the records.

(6) For research involving more than minimal risk, an explanation as to whether any compensation and an explanation as to whether any medical treatments are available if injury occurs and, if so, what they consist of, or where further information may be obtained.

(7) An explanation of whom to contact for answers to pertinent questions about the research and research subjects' rights, and whom to contact in the event of a researchrelated injury to the subject.

(8) A statement that participation is voluntary, that refusal to participate will involve no penalty or loss of benefits to which the subject is otherwise entitled, and that the subject may discontinue participation at any time without penalty or loss of benefits to which the subject is otherwise entitled.

(b) Additional elements of informed consent. When appropriate, one or more of the following elements of information shall also be provided to each subject: 
(1) A statement that the particular treatment or procedure may involve risks to the subject (or to the embryo or fetus, if the subject is or may become pregnant) which are currently unforeseeable.

(2) Anticipated circumstances under which the subject's participation may be terminated by the investigator without regard to the subject's consent.

(3) Any additional costs to the subject that may result from participation in the research.

(4) The consequences of a subject's decision to withdraw from the research and procedures for orderly termination of participation by the subject.

(5) A statement that significant new findings developed during the course of the research which may relate to the subject's willingness to continue participation will be provided to the subject.

(6) The approximate number of subjects involved in the study.

(c) When seeking informed consent for applicable clinical trials, as defined in 42

U.S.C. 282(j)(1)(A), the following statement shall be provided to each clinical trial subject in informed consent documents and processes. This will notify the clinical trial subject that clinical trial information has been or will be submitted for inclusion in the clinical trial registry databank under paragraph (j) of section 402 of the Public Health Service Act. The statement is: "A description of this clinical trial will be available on http://www.ClinicalTrials.gov, as required by U.S. Law. This Web site will not include information that can identify you. At most, the Web site will include a summary of the results. You can search this Web site at any time."

(d) The informed consent requirements in these regulations are not intended to preempt any applicable Federal, State, or local laws which require additional information to be disclosed for informed consent to be legally effective.

(e) Nothing in these regulations is intended to limit the authority of a physician to provide emergency medical care to the extent the physician is permitted to do so under applicable Federal, State, or local law.

[46 FR 8951, Jan. 27, 1981, as amended at 76 FR 270, Jan. 4, 2011] 


\section{ANEXO VII \\ Relatório da European Medicines Agency (EMA) da União Europeia contendo os registros de testes de medicamentos com sujeitos nacionais de países não membros. ${ }^{669}$}

Figure 4. Third countries with at least $0.5 \%$ of patients in the pivotal trials included in the MAA submitted to the Agency during the 2005-2011 period.

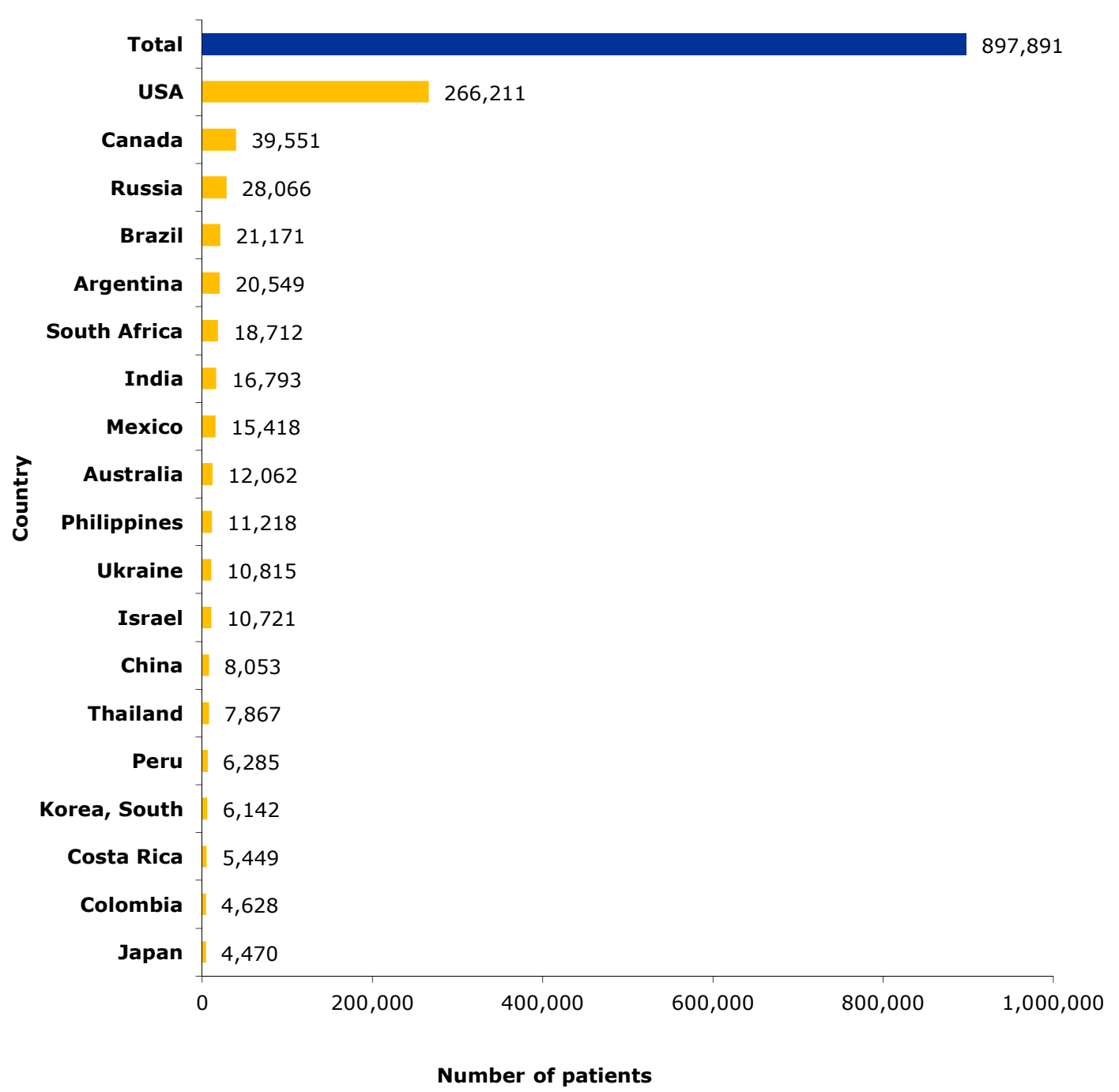

${ }^{669}$ EUROPEAN MEDICINES AGENCY, Clinical trials submitted in marketing-authorisation applications to the European Medicines Agency Overview of patient recruitment and the geographical location of investigator sites Containing data from 2005 to 2011, 2013, p. 13. Disponível online em: http://www.ema.europa.eu/docs/en GB/document library/Other/2009/12/WC500016819.pdf Acesso em 0505-2018 